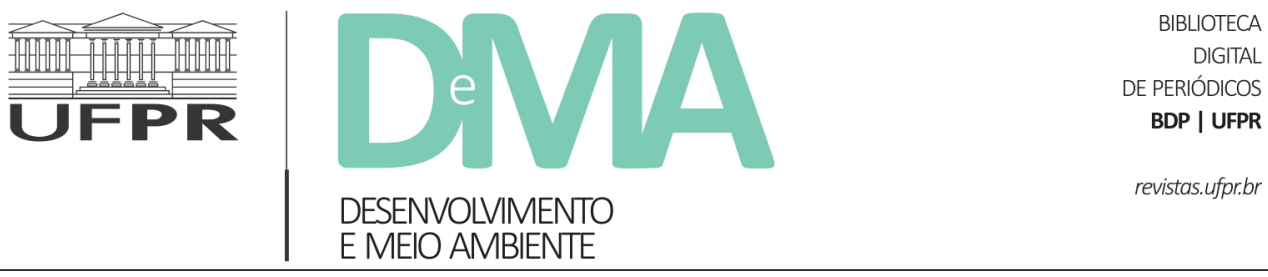

\title{
Governança ambiental em áreas marinhas protegidas: 0 contexto do Arquipélago de Fernando de Noronha, Brasil
}

\section{Environmental governance in marine protected areas: the context of the Fernando de Noronha archipelago, Brazil}

\author{
Aline Guzenski FIORAVANSO ${ }^{1}$, João Luiz NICOLODI ${ }^{2 *}$ \\ ${ }^{1}$ Universidade Federal do Rio de Janeiro (UFRJ), Rio de Janeiro, RJ, Brasil. \\ ${ }^{2}$ Universidade Federal de Rio Grande (FURG), Rio Grande, RS, Brasil. \\ *E-mail de contato: jl.nicolodi@bol.com.br
}

Artigo recebido em 29 de maio de 2020, versão final aceita em 6 de abril de 2021, publicado em 08 de dezembro de 2021.

\begin{abstract}
RESUMO: $\quad$ As áreas marinhas protegidas fazem parte de uma estratégia global de conservação da biodiversidade, uma vez que essas áreas apresentam alta riqueza biológica, sendo base para diferentes serviços ecossistêmicos. Em diversas ilhas e arquipélagos o turismo se constitui como principal atividade econômica, usufruindo dos resultados de um ambiente protegido. Porém, o turismo não controlado tornou-se a principal causa de degradação e destruição em ecossistemas insulares, sendo consequência direta de falhas na governança destes espaços. Neste contexto, o presente estudo teve como objetivo analisar a governança ambiental no Arquipélago de Fernando de Noronha (Brasil). Os dados foram coletados através de observação direta e entrevistas com atores-chave, sendo analisados pela abordagem da Policy Analysis e a partir da utilização do software MACTOR. Os resultados obtidos sugerem que, na ilha principal (a única habitada), o paraíso é substituído por graves conflitos socioambientais, caracterizados por problemas ambientais tipicamente urbanos e disputas de poder entre os atores sociais. A má gestão, a falta de integração entre as instituições e o não cumprimento às restrições ambientais podem gerar uma situação de colapso em termos sociais, ambientais e econômicos no arquipélago.
\end{abstract}

Palavras-chave: governança ambiental; áreas marinhas protegidas; gestão ambiental.

ABSTRACT: Marine protected areas are part of a global biodiversity conservation strategy, since these areas have high biological richness and are the basis for different ecosystem services. On many islands and archipelagostourism is the main economic activity, taking advantage of the results of a protected environment. However, uncontrolled tourism has become the main cause of degradation and destruction in island ecosystems, being a direct consequence offailures in the governance of thesespaces. In this context, the present study aimed to analyze the environmental governance in the Fernando de Noronha Archipelago (Brazil). Data were collected 
through direct observation and interviews with key actors, and analyzed using the Policy Analysis approach and the MACTOR software. The results obtained suggest that on the main island (the only inhabited), paradise is replaced by serious socio-environmental conflicts, characterized by typically urban environmental problems and political disputes between social actors. Poor management, the lack of integration between institutions and non-compliance with environmental restrictions can lead to a situation of collapse in social, environmental and economic terms in the archipelago.

Keywords: environmental governance; marine protected areas; environmental management.

\section{Introdução}

Áreas Marinhas Protegidas (AMPs) têm como objetivo a proteção da biodiversidade e apresentam alguma forma de restrição de uso dos recursos provenientes de seus ambientes naturais (Stevenson $\&$ Tissot, 2013). São áreas com enfoque na proteção do ambiente marinho que podem incluir áreas terrestres e ilhas ao compreender a zona intermarés (intertidal) ou abaixo do nível do mar (subtidal) abrangendo a coluna d'água associada com fauna e flora (Kelleher, 1999).

As AMPs contribuem para a geração de benefícios mútuos entre ambiente e economia, ao passo que orientam diretrizes de gestão para utilização de recursos de forma a promover o equilíbrio da natureza, o que, consequentemente,tem potencial para atrair o setor turístico. Nesse contexto, ilhas e arquipélagos são importantes, pois representam a manutenção de processos ecológicos básicos da vida marinha. Em algumas localidades a atividade turística se configura como uma das principais alternativas para seu desenvolvimento socioeconômico, como pode ser observado em ilhas mais conhecidas como Ibiza, Cozumel, Açores, Canárias, Seychelles, Galápagos (Körössy, 2007) ou menos conhecidas como as ilhas Lakshadweep, na Índia (Kokkranikal \& McLellan, 2010). Porém, além de prover benefícios sociais às comunidades locais, o turismo também pode afetar negativamente a comunidade ao intensificarconflitos socioambientais, podendo, ainda, se tornar uma das principais causasde degradação de ecossistemas insulares (Bennett \& Dearden, 2014; Rees et al., 2015; Carvalho et al., 2016).

A gestão das AMPs segue quatro modelos básicos que foram definidos por Jones et al. (2019): estatal, compartilhado, privado e comunitário. Suas estratégias devem conciliar características ecológicas e socioeconômicas, considerando a manutenção de seus sistemas subaquáticossensíveis ao equilíbrio ambiental (Fournier \& Panizza, 2003). Esses ambientes são geralmente afetados por atividades humanas desregradas e sofrem com problemas ambientais externos como a poluição marinha e a sobrepesca (Ehler, 2003). Por estas razões, a efetividade da AMP depende do planejamento e da implementação de uma gestão integrada que aplique boas práticas de governança, considerando a economia local e o bom relacionamento com a comunidade (Cárcamo et al., 2014; Bennett \& Dearden, 2014).

As atuais metas da Convenção sobre Diversidade Biológica (CDB) e dos Objetivos de Desenvolvimento Sustentável das Nações Unidas (ODS) preveem a implementação de proteção eficaz e equitativa de ambientes marinhos e costeiros. Apesar do progresso significativo dos países signatários, ainda há considerações e ações insuficientes sobre eficiência no que diz respeito à governança, o que 
pode ser uma ameaça à capacidade de atingir objetivos de conservação (Jones et al., 2019). Evidências relacionadas ao contexto social de planejamento e gestão de AMPs têm mostrado que o papel das partes interessadas (stakeholders) é fundamental (Di Franco et al., 2016). A governança ambiental mostra-se um instrumento indispensável, pois determina o formato das tomadas de decisões e influencia o comportamento dos indivíduos (Aburto et al., 2017; Glaser et al., 2018).

Entende-se que a governança na esfera da gestão ambiental pública seja o resultado da cooperação entre os entes e da participação social prevista na Constituição Federal (Moura, 2016). Cavalcanti (2004) considera que, na esfera pública, a governança é utilizada como referência ao processo contínuo capaz de moldar a forma como os poderes são exercidos através do envolvimento de complexos arranjos.

Considerando tais conceitos, pode-se apontar que falhas de governança são responsáveis pelo não enfrentamento de problemas ambientais atuais (Epstein et al., 2015) e, nesse sentido, a compreensão sobre a motivação dos atores envolvidos é capaz de apontar a origem de tais falhas, indicando o nível de congruência entre instituições responsáveis e os demais stakeholders (Yates et al., 2019). De forma geral, fatores como engajamento de stakeholders, formato de governança, vontade política e a existência de mecanismos de sanção e resolução de conflitos são apontados como os fatores que mais afetam o sucesso de AMPs (Giakoumi et al., 2018).

No Brasil, a capacidade de respostaa este tipo de questão depende de uma estrutura de governança complexa estabelecida pelo Sistema Nacional de Meio Ambiente (SISNAMA) e pelo Sistema Nacional de Unidades de Conservação - SNUC (Brasil,
2000), onde diferentes entes federativos devem ser articulados para a implementação de regrase políticas ambientais (Moura, 2016). Essa governança perpassa as estruturas de governo, mostrando-se um complexo jogo de pressões e representações entre instituições, setores econômicos e representações da sociedade civil (Bursztyn \& Bursztyn, 2012).

Atualmente, existem 187 áreas marinhas protegidas no Brasil (UCs), abrangendo 26,5\% do bioma marinho (ICMBIO, 2020). Como forma de analisar a eficiência na gestão em UCs, são considerados elementos estáticos inerentes à gestão pública, tais como existência de planos de manejo, conselhos gestores e outras ferramentas de gestão participativa (Queiroz, 2002; Padovan \& Lederman, 2004; Lima Filho, 2006). Poucos são os estudos que analisam experiências mais duradouras e empíricas, os quais envolvam relações entre atores e não os níveis de efetividade da gestão (Lobão, 2006; Macedo, 2008; Cardozo et al., 2012; Carvalho et al. 2016).

Em linhas gerais, pode-se dizer que no Brasil os índices de eficiência da gestão de UCs costeiras e marinhas são em geral medianamente satisfatórios, como verificado na análise RAPPAM realizada com 44UCs marinhas entre os anos 2005-2011 (Ogana et al. 2012) e nos casos da APA Estadual Recifes de Corais, APA Federal Costas dos Corais, RESEX Marinha Federal Corumbau, APA Estadual Ponta da Baleia/Abrolhos (Prates, 2003) e Parque Estadual Marinho da Pedra da Risca do Meio (Lima Filho, 2006; Soares et al. 2010).

Por outro lado, dados mais atuais mostram que os princípios da boa governança vêm ampliando a participação social através de conselhos gestores (Cardoso et al., 2019), porém, paradoxos e desafios relativos a aspectos de representatividade, independência, influência e compartilhamento genuíno de 
poder em processos de tomada de decisões ainda demandam atenção (Prado et al., 2020). Recentemente, Figueiredo \& Nicolodi (2020) desenvolveram um modelo dinâmico de avaliação de boas práticas em gestão costeira integrada que pode ser aplicado em análises como as supracitadas.

Inserido no SNUC através de duas UCs, Fernando de Noronha apresenta um sistema de gestão público conflituoso quando considerado seu ordenamento jurídico. Sua configuração envolve três principais abordagens: a) territorial, uma vez que pertence à União por ser uma ilha oceânica, conforme o Art. 20, inciso IV da Constituição Federal (Brasil, 1988a); b) administrativa, uma vez que pertence ao estado de Pernambuco, conforme o Art. 15 da Constituição Federal (Brasil, 1988a) e; c) ambiental, já que deve ser gerida pelo órgão competente, segundo o Art. $6^{\circ}$ da Lei Federal 9.985/2000 (Brasil, 2000).

Apesar de contar com todas as estruturas necessárias para a efetivação de uma boa governança ambiental, Noronha convive com problemas ambientais e conflitos significantes entre os atores sociais (Abdala, 2008; Cleto, 2013; Cordeiro \& Körössy, 2018). Nesse sentido, o presente trabalho analisa a governança ambiental de Fernando de Noronha, apresentando as falhas que levam ao contexto socioambiental observado no arquipélago.

\section{1. Área de estudo}

Fernando de Noronha é um arquipélago internacionalmente conhecido por suas características naturais, e considerado, desde 2001, Patrimônio Mundial dentro do grupo de Ilhas Atlânticas Brasi- leiras (UNESCO, 2015). Atualmente, é um Distrito Estadual administrado pelo estado de Pernambuco, distante $545 \mathrm{~km}$ da capital, Recife, e com população oficial estimada em 3.061 habitantes. Na ilha principal, a única habitada e correspondente a 17 $\mathrm{km}^{2}$ de extensão, concentram-se as atividades socioeconômicas do arquipélago, sendo o turismo o setor econômico predominante (IBGE, 2020).

Devido a sua importância biológica, o arquipélago é protegido através de duas AMPs: Área de Preservação Ambiental Estadual (APA) de Fernando de Noronha-Rocas-São Pedro e São Paulo (Brasil, 1986) e Parque Nacional Marinho (PARNAMAR) de Fernando de Noronha (Brasil, 1988b).

$\mathrm{O}$ arquipélago possui $26 \mathrm{~km}^{2}$ de área e é constituído por 21 ilhas, representando o topo do cone vulcânico de uma montanha submarina, cuja base se situa a cerca de $4.200 \mathrm{~m}$ de profundidade (Almeida, 2015). Noronha é considerada uma das áreas prioritárias para a conservação (MMA, 2007), pois é umoásis para a manutenção das comunidades marinhas e espécies endêmicas, abrigando o único manguezal oceânico do Atlântico Sul e constando entre as Reservas da Biosfera da Mata Atlântica (IBAMA, 2005).

Atualmente, a área do PARNAMAR corresponde a $70 \%$ do arquipélago (aprox. $11.270 \mathrm{ha}$ ), a qual se somam todas as ilhas e ilhotas situadas ao redor da ilha principal. Os demais $30 \%$ são correspondidos pela APA, área onde se localiza a porção urbanizada do território (Figura 1). O PARNAMAR abriga os principais pontos turísticos com limite de visitação e na APA localizam-se as praias que recebem mais visitantes (IBAMA, 2005). 


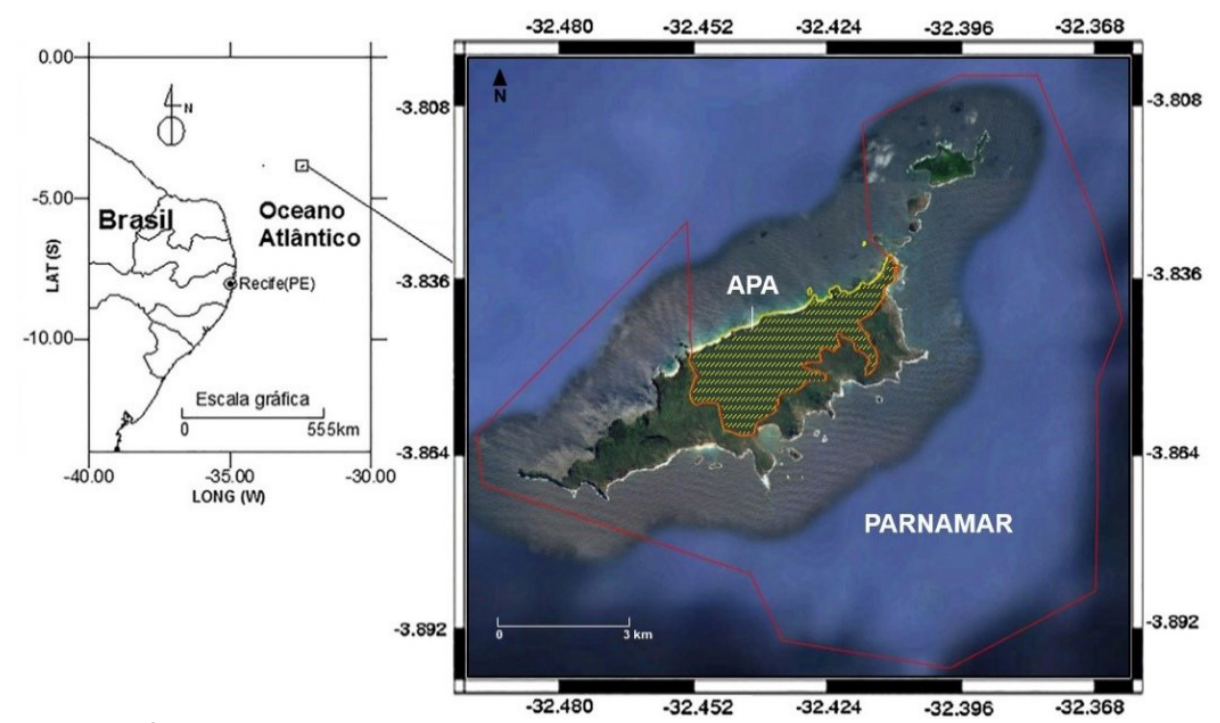

FIGURA1 - Demarcação daÁrea de Preservação Ambiental (APA) e do Parque Nacional Marinho (PARNAMAR) de Fernando de Noronha. FONTE: Elaborado pelos autores. Imagem de satélite cedida pela Superintendência do Patrimônio da União.

\section{Metodologia}

Análises sobre a gestão pública buscam compreender as ações dos indivíduos, suas manifestações coletivas e o desenvolvimento de políticas. As instituições podem ser vistas como um complexo palco de análise, pois atuam como mediadores entre as estruturas sociais e os comportamentos individuais (Théret, 2003). No campo da ciência política, o institucionalismo consolidou-se como uma ferramenta teórica e metodológica que percebia as instituições como estruturas estáveis e mantidas por meio de mecanismos constantes de reprodução institucional. Já o neoinstitucionalismo foi sistematizado por Hall \& Taylor (1996), produzindo um conjunto de novos conceitos, categorias e relações causais para a compreensão da interação entre atores e instituições. Dessa forma, cria-se a visão de que o processo decisório influencia a tomada de decisão dos atores e, portanto, instituições condicionam a atuação dos atores através de regras que moldam comportamentos (Troiano \& Riscado, 2016).

Essa visão integrada denota a existência de diferentes dimensões políticas que influenciam o formato de governança na gestão pública. A $P_{o}$ licy Analysis traz a diferenciação teórica dos três aspectos peculiares da política, conhecidos como "Polity", "Politics" e "Policy", fornecendo três categorias analíticas: o ambiente institucional (Dimensão institucional - "Polity"), o relacionamento dinâmico entre os atores (Dimensão processual "Politics") e a conjuntura atual (Dimensão material - "Policy") (Frey, 2000).

Neste contexto, o método Policy Analysis foi utilizado na investigação sobre as dimensões institucional, processual e material da gestão ambiental pública de Fernando de Noronha. Estas três dimensões se inter-relacionam, trazendo um pano- 
rama contextualizado entre o arranjo institucional observado, a atuação das instituições frente aos objetivos estabelecidos e a realidade socioambiental vivenciada na ilha (Tabela 1). Esse método apresenta um potencial analítico abrangente, pois supera abordagens isoladas das dimensões institucionais ou políticas-processuais, mostrando como o ambiente institucional e suas dinâmicas de funcionamento influenciam no panorama da gestão e governança.

A descrição analítica do papel das instituições-chave foi elaborada através da ferramenta "Jogo dos Atores (MACTOR)" proposto por Godet (1991), onde são observados os formatos de ação de cada ator, composto por histórico, objetivos, ações, forças e fraquezas. A ferramenta conta com 4 etapas: (1) Definiçãodos atores e compreensão de suas estratégias; (2) Análise de influências entre atores e avaliaçãodas relações de força; (3) Identificação de temas estratégicos e objetivos associados; (4) Identificação de convergências/divergências de atuação. Os posicionamentos dos atores frente aos objetivos foram avaliados com o software livre ${ }^{\circledR}$ LIPSOR-EPITA-MACTOR a partir de cálculos matriciais entre Matriz de Influência Direta (MID) e Matriz de Posições Valoradas (MAO), onde são atribuídos valores aos meios de ação (MID) e às atitudes de cada ator em relação a cada objetivo (MAO) (Godet \& Durance, 2015).

Em MID, a valoração foi feita de acordo com o grau de influência de um ator sobre o outro observado ao longo do levantamento de dados, considerando os valores de: 0 quando o ator tem pouca influência ou nenhuma sobre outro ator; 1 quando o ator pode limitar os processos operatórios de outro ator; 2 quando o ator pode promover a realização dos projetos do outro ator; 3 quando o ator pode promover o cumprimento das missões do outro ator; e 4 quando o ator pode promover a existência do outro ator.

Em MAO, a valoração considerou se existe acordo, desacordo ou neutralidade em relação a cada objetivo analisado, atribuindo-se os valores de: 0 quando o objetivo é pouco consequente; 1 quando o objetivo tem consequência ou é indispensável para o bom funcionamento dos processos; 2 quando o objetivo tem consequência ou é indispensável para a realização dos projetos; 3 quando o objetivo tem consequência ou é indispensável para o cumprimento da missão; e 4 quando o objetivo tem consequências sobre a existência do ator ou é indispensável para sua perenidade.

TABELA 1 - Quadro-resumo do método Policy Analysis (Frey, 2000) aplicado neste estudo.

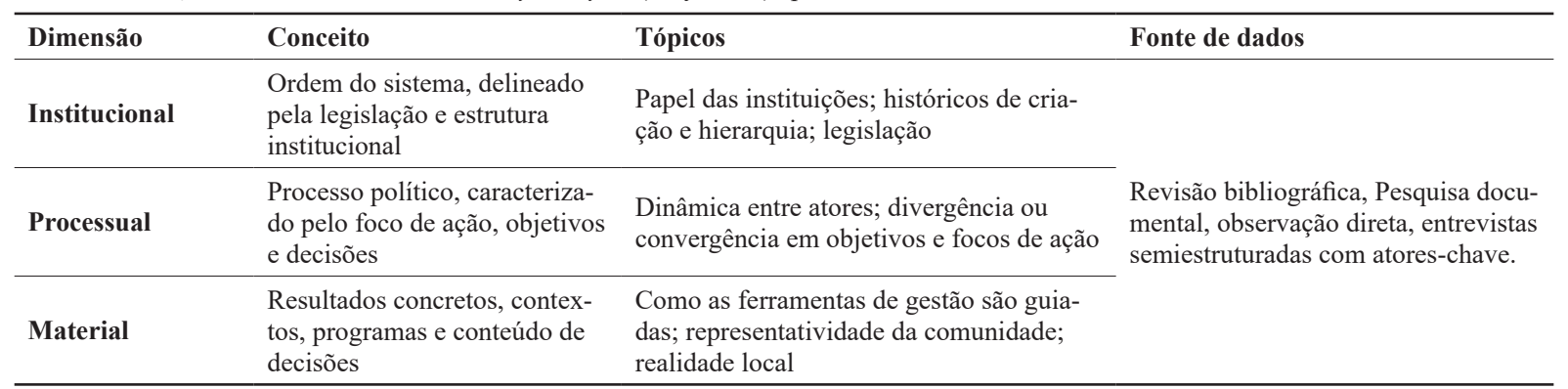

FONTE: Adaptado de Frey (2000). 
As informações utilizadas como inputs dos modelos foram levantadas a partir de observação direta, entrevistas semiestruturadas com atores-chaves identificados, pesquisa documental e revisão bibliográfica. A observação direta foi realizada no período de julho de 2016 a março de 2017 com apoio do Programa de Voluntariado NGI-Noronha/ ICMBio. Foram observadas atividades relacionadas aos instrumentos de gestão participativa na ilha envolvendo diferentes atores: 15 reuniões internas nas instituições gestoras das áreas protegidas (ICMBio) e do distrito (Autarquia Territorial do Distrito Estadual de Fernando de Noronha - ATDEFN), 6 reuniões do conselhogestor da APA e PARNAMAR (Conselho ICMBio), 3 reuniões do Conselho de Turismo (CONTUR) e 3 oficinas participativas com a comunidade.

Após 3 meses de observação direta, foram realizadas 15 entrevistas, analisadas através da transcrição literal com o objetivo de compreender as motivações de cada ator-chave. Estes atores foram escolhidos conforme sua atuação no processo de gestão e disponibilidade, considerando as Organizações ATDEFN (3 representantes), ICMBio (3 representantes), MPPE (1 representante), SPU-PE (1 representante) e Conselho Distrital (3 representantes). Também foram entrevistados 2turismólogos atuantes na ilha e 2 moradores locais.

As entrevistas abordaram os problemas ambientais, os conflitos sociais e as percepções sobre as ações das instituições-chave, sendo que elas seguiram os protocolos preconizados pelo Comitê de Ética da Universidade Federal do Rio Grande $(\text { FURG })^{1}$. Esta pesquisa encontra-se cadastrada no Sistema de Autorização e Informação em Biodi- versidade (SISBIO), sob o número 53211-1/2016. Antes do início da coleta de dados, o projeto foi apresentado ao gestor do Núcleo de Gestão Integrada de Fernando de Noronha (NGI-Noronha) para anuência. Os resultados foram apresentados à comunidade noronhense como devolutiva em março de 2017 durante uma oficina participativa organizada pela Superintendência do Patrimônio da União de Pernambuco (SPU-PE).

\section{Resultados e discussão}

Historicamente, Fernando de Noronha apresenta uma administração volátil, a qual perpassou períodos distintos desde a falta de interesse da Corte Portuguesa, a utilização como um grande sistema defensivo de fogo cruzado, a utilização como Colônia Correcional, transformada em Presídio Político em 1938 (fechado em 1942 e reaberto após o golpe de 1964) até a abertura para um turismo ainda incipiente em 1969. Esta atividade torna-se intensaapós a criação de suas áreas protegidas e anexação do distrito ao estado de Pernambuco entre os anos de 1986 e 1988 (Silva, 2007).

Em 1988 Fernando de Noronha passou a ser um distrito de Pernambuco, único em sua categoria no Brasil, dotado de estatuto próprio e com autonomia administrativa e financeira, segundo o artigo 96, $\S 3^{\circ}$ da Constituição do Estado de Pernambuco (Pernambuco, 1989a). Curiosamente, a criação do PARNAMAR foi apontada na época como uma estratégia do governo federal para manter o poder administrativo sobre a maior parte do território de Noronha (Cleto, 2013). Esse breve histórico elucida

\footnotetext{
${ }^{1}$ ResoluçãoFURG no 466/2012.
} 
a importância de se compreender a herança histórica que acompanha a formatação de sistemas de governança, pois essas heranças tendem a se refletir nas ações tomadas pelos stakeholders (Frey, 2000; Godet \& Durance, 2015).

Atualmente, todas as UCs federais são geridas pelo Instituto Chico Mendes de Conservação da Biodiversidade (ICMBio), sendo que desde 2017 a gestão das UCs é representada pelo Núcleo de Gestão Integrada do ICMBio (NGI-Noronha/ICMBio) (ICMBio, 2017a). A gestão administrativa da APA cabe exclusivamente à ATDEFN, comandada por um Administrador Geral indicado diretamente pelo Governador de Pernambuco. Quanto à gestão territorial, a Superintendência do Patrimônio da União (SPU) é responsável por administrar o contrato de cessão de uso celebrado em 2002 que repassou a gestão administrativa da APA à ATDEFN.

Ainda que a administração local (ATDEFN) seja ligada ao Governo do estado de Pernambuco, a mesma administração apresenta atribuições análogas a de um município. O único órgão relacionado à regulamentação ambiental é a Agência Estadual de Meio Ambiente (CPRH). Ao mesmo tempo, o Ministério Público é representado por uma promotoria específica para o arquipélago. A Figura 2 ilustra esse arranjo e, embora o nível municipal não faça parte da administração específica de Fernando de Noronha, ele foi inserido para fins didáticos acerca do SISNAMA.

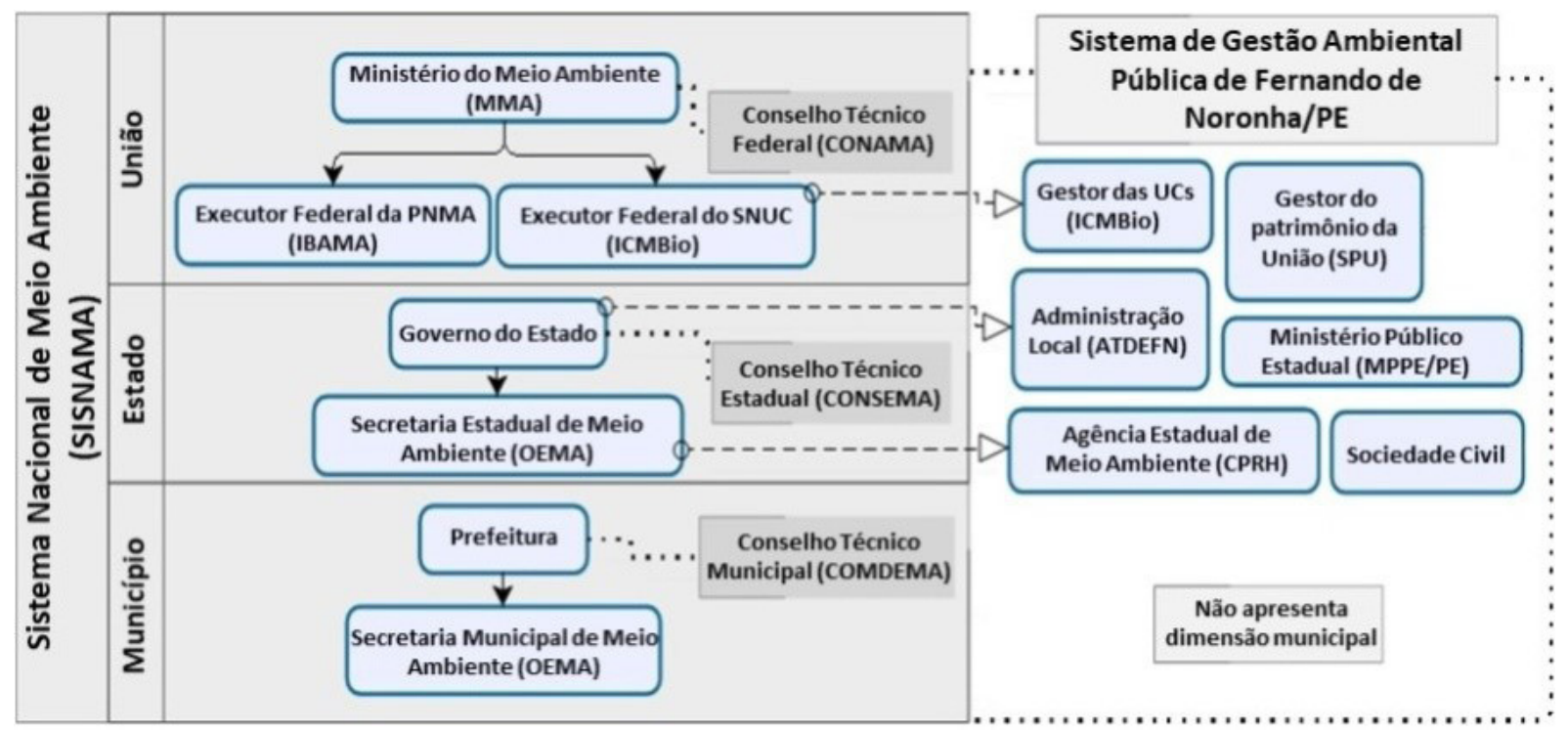

FIGURA 2 - Esquema mostrando a relação entre a estrutura prevista no SISNAMA e o Sistema de Gestão Ambiental Pública de Fernando de Noronha identificado por este estudo.

FONTE: Elaborado pelos autores. 


\subsection{Dimensão institucional: sistema de gestão compartilhada}

Os cinco atores principais da gestão ambiental foram caracterizados conforme seus perfis de atuação observados ao longo do período de coleta de dados (Tabela 2). Identificou-se um "eixo principal" composto por ATDEFN e ICMBio devido às suas responsabilidades e tratativas para a gestão do arquipélago de forma conjunta, considerando a existência de uma área urbana composta pela APA, onde a ATDEFN tem poder decisório, e a área do PARNAMAR, onde o ICMBio, através do NGI-Noronha, tem autonomia para gerir. Dentro do recorte ambiental, identificou-se que a CPRH, o MPPE e a SPU apresentam-se como importantes mediadores entre ATDEFN e ICMBio, com diferentes atribuições.

No PARNAMAR, de caráter mais restritivo, o ICMBio possui plena competência para gestão. Já na área da APA, menos restritiva, o papel inverte-se, pois a legislação vigente atribui caráter supletivo ao ICMBio para ações de gestão ambiental, como a fiscalização, cuja prerrogativa é repassada ao

TABELA 2 - Caracterização da atuação, forças e fraquezas dos atores identificados no sistema da Gestão Ambiental Pública de Fernando de Noronha.

\begin{tabular}{|c|c|c|c|}
\hline Ator & Foco de atuação & Força & Fraqueza \\
\hline $\begin{array}{l}\text { Autarquia } \\
\text { Territorial do } \\
\text { Distrito Estadual } \\
\text { de Fernando de } \\
\text { Noronha ATDEFN }\end{array}$ & $\begin{array}{l}\text { Política socioeconômica, adminis- } \\
\text { tração de serviços públicos, controle } \\
\text { migratório, cessão de terrenos para } \\
\text { uso }\end{array}$ & $\begin{array}{l}\text { Competência de atuação na APA para } \\
\text { regular atividades impactantes ao } \\
\text { meio natural }\end{array}$ & $\begin{array}{l}\text { Pouca articulação com o ICMBio } \\
\text { e baixa priorização para atuação } \\
\text { em questões ambientais }\end{array}$ \\
\hline
\end{tabular}
mento e fiscalização da utilização

ICMBio do território, execução de atividades educativas
Ampla gerência no PARNAMAR e equipe técnica capacitada
Enfoque maior no PARNAMAR, deixando as questões da APA em segundo plano

$\begin{array}{lll}\text { Agência } & \text { Licenciamento ambiental de em- } & \begin{array}{l}\text { Competência para licenciar empreen- } \\ \text { Estadual de Meio } \\ \text { preendimentos e atividades econô- }\end{array} \\ \text { AmbienteCPRH } & \text { micas } & \begin{array}{l}\text { dimes na APA e boa comunicação } \\ \text { com a ATDEFN }\end{array}\end{array}$

Agência

AmbienteCPRH preendimentos e atividades econô dimentos na APA
com a ATDEFN
Pouca articulação com o ICMBio, observação parcial ao plano de manejo em processos licenciatórios $^{1}$

\begin{tabular}{ll}
\hline $\begin{array}{l}\text { Ministério Público } \\
\text { de Pernambuco }\end{array}$ \\
$\begin{array}{l}\text { Promotoria de } \\
\text { Fernando de } \\
\text { Noronha }\end{array}$ & $\begin{array}{l}\text { Regulação de órgãos públicos frente } \\
\text { ao cumprimento da legislação vigente }\end{array}$
\end{tabular}

Competência para mediar ou cobrar ações e garantir o cumprimento da lei, atua como mediador de conflitos
Não possui competência sobre a esfera da União

MPPE

\section{Superintendência do Patrimônio da} União

SPU-PE
Regulação da ATDEFN quanto ao cumprimento do contrato estabelecido
Veda situações em que a preservação ambiental seja comprometida, atua como mediador de conflitos
Foi omissa ${ }^{2}$ nos últimos anos quanto à fiscalização do contrato com ATDEFN

\footnotetext{
${ }^{1}$ dado coletado em observação direta de reunião interna entre ICMBio, ATDEFN, SPU e CPRH;

${ }^{2}$ conforme relatório de auditoria ${ }^{\circ} 201316876$ da Controladoria-Geral da União (CGU) e entrevistas realizadas.

FONTE: Os autores.
} 
CPRH. Esse fato torna o ICMBio um ator coadjuvante na administração pública referente à APA, responsável, na prática, apenas pelo cumprimento de requisitos legais ambientais como a elaboração do plano de manejo e implementação do conselho gestor da unidade.

Tanto a ATDEFN quanto o ICMBio apresentam atualmente políticas de gestão participativa, onde os envolvidos encontram espaços para reivindicações e até decisões em conjunto. SPU e MPPE também contribuem nessa temática, principalmente por seu papel de ouvir e esclarecer a comunidade. Nesse âmbito, existem instrumentos que podem ser considerados permanentes (conselhos), pontuais (reuniões, fóruns de debate, audiências públicas) ou específicos a um tema (grupos de trabalho, comitês).

Além da ATDEFN, a administração do distrito conta com um Conselho Distrital, de caráter apenas consultivo, composto por sete conselheiros a serem eleitos pelo voto direto dos residentes da ilha. Como o administrador geral apenas depende de prévia aprovação da Assembleia Legislativa, sem a necessidade de participação popular (Pernambuco, 1989a), a formação do conselho supriria essa demanda, porém os conselheiros eleitos nem sempre representam os interesses da comunidade (Reis \& Hayward, 2013). Suas pautas concentram-se em temáticas socioeconômicas, por vezes antagônicas aos interesses da conservação ambiental, como o caso do aumento da zona urbana na nova versão do plano de manejo da APA revisado em 2017 (Marinho, 2017). As discussões sobre a revisão do plano de manejo e outras pautas foram acompanhadas durante a observação direta nesta pesquisa. Dessa forma, o Conselho Distrital não foi considerado um ator chave nesse estudo de caso.

Este emaranhado político-institucional-administrativo conta ainda com inúmeras organizações ativas da sociedade civil que têm papéis na gestão ambiental pública da ilha, como instituições ambientais e associações setoriais. Todas as instituições relacionadas à temática ambiental podem ser observadas no conselho consultivo integrado APA/PARNAMAR (Figura 3), composto por 12 instituições representantes do Poder Público e 16 da Sociedade Civil (Tabela 3).

O Conselho de Turismo (CONTUR), de caráter consultivo, também foi considerado relevante para a temática ambiental, pois é composto em maioria pelas mesmas instituições do conselho APA/PARNAMAR e apresenta maior objetividade em suas pautas de discussão, sendo estratégico e indispensável para conciliar as atividades econômicas da ilha com o desenvolvimento sustentável. As pautas discutidas no CONTUR que demandam uma atuação mais incisiva do poder público, como a política de não utilização de recicláveis na ilha, são levadas à ATDEFN, instituição com capacidade de implementar e gerenciar ações administrativas.

\subsection{Dimensão processual: jogo dos atores}

Em Fernando de Noronha nota-se uma grande diferença de tratativas entre as esferas de poder (União/Estado). O histórico noronhense mostra o embate entre as esferas estadual e federal desde a anexação do distrito a Pernambuco e criação do PARNAMAR. Esse embate ainda pode ser caracterizado pela omissão dos órgãos estaduais no cumprimento de suas atribuições ambientais e pela atuação incisiva do ICMBio ao implementar medidas de conservação e fiscalização, como mostra o trecho de uma das entrevistas realizadas com representante da ATDEFN: 


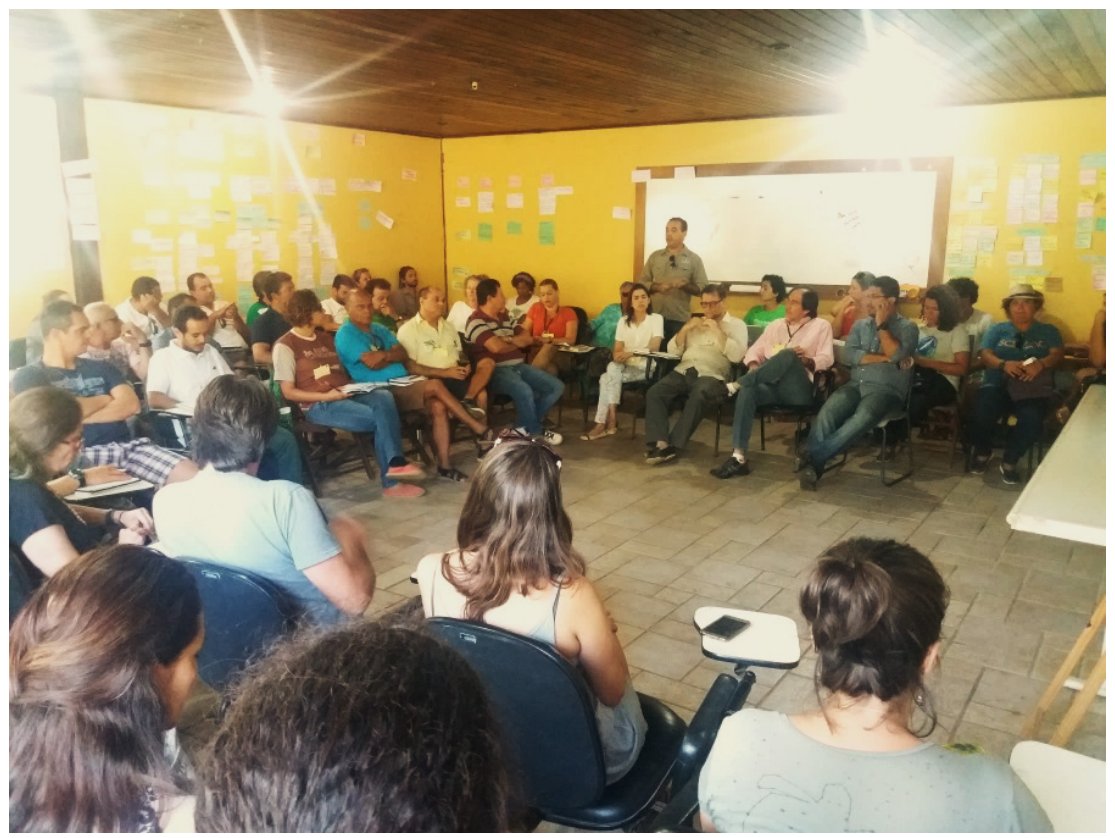

FIGURA 3 - Reunião do conselho gestor da APA em 2016.

FONTE: Acervo de Aline Fioravanso.

Durante muito tempo o ICMBio se sobrepôs por falta do Estado e foi ausência mesmo da ATDEFN e da CPRH, e aí o ICMBio tomou conta. Eu acho justo, alguém tinha que fazer isso. Mas aí tem gestões e gestões. Algumas foram mais conservacionistas e pegaram mais pesado com a população. Tenho que concordar com a comunidade que tem que separar, uma coisa é Parque outra coisa é APA. E não se fazia isso, era muito autoritário. Não que eu não concorde (risos), mas eu sei que não é assim. A gente como Estado precisa olhar pras pessoas. Elas fazem parte.

Além disso, as divergências entre as instituições ICMBio/ATDEFN têm relação com os objetivos de cada instituição, cujas políticas podem mudar conforme a gestão, mas em geral o enfoque permanece o mesmo. Para a ATDEFN, o foco prin- cipal é a política social e econômica com as quais administra a urbanização e seus serviços públicos. Apesar de contar com o valor arrecadado pela Taxa de Preservação Ambiental (TPA), cujo objetivo é "assegurar as condições ambientais e ecológicas do território" (Pernambuco, 1989b), a gestão ambiental da ATDEFN foi apontada como incipiente por um dos representantes do próprio órgão devido à falta de equipe:

É uma linha política que no estado de Pernambuco não é prioridade o meio ambiente. Isso é fato. Isso dificulta a gestão de meio ambiente. [...] Porque se não é uma prioridade, não vão dar prioridade na contratação de pessoal. 
TABELA 3 - Lista de instituições componentes dos conselhos APA/PARNAMAR (ICMBio) e Turismo (CONTUR).

\begin{tabular}{|c|c|c|}
\hline \multirow{2}{*}{ Poder Público } & \multicolumn{2}{|c|}{ Conselho } \\
\hline & ICMBio & CONTUR \\
\hline \multicolumn{3}{|l|}{ 1. Órgão gestor de ambas as UCs (ICMBio) } \\
\hline \multicolumn{3}{|c|}{ 2. Comando da Aeronáutica/Controle do Espaço Aéreo de FN (DPV) } \\
\hline \multicolumn{3}{|l|}{ 3. Marinha do Brasil/Capitania dos Portos (CPPE) } \\
\hline \multicolumn{3}{|l|}{ 4. Universidade Federal de Pernambuco (UFPE) } \\
\hline \multicolumn{3}{|l|}{ 5. Universidade Federal do Rio Grande do Norte (UFRN) } \\
\hline \multicolumn{3}{|c|}{ 6. Secretaria de Meio Ambiente e Sustentabilidade de Pernambuco (SEMAS) } \\
\hline \multicolumn{3}{|c|}{ 7. Autarquia do Distrito Estadual de Fernando de Noronha (ATDEFN) } \\
\hline \multicolumn{3}{|l|}{ 8. Conselho Distrital de Fernando de Noronha (CDFN) } \\
\hline \multicolumn{3}{|c|}{ 9. Instituto do Patrimônio Histórico Artístico Nacional/Pernambuco (IPHAN/PE) } \\
\hline \multicolumn{3}{|c|}{ 10. Centro de Pesquisa e Conservação de Mamíferos Aquáticos (ICMBio/CMA) } \\
\hline \multicolumn{3}{|c|}{ 11. Agência Estadual de Meio Ambiente de Pernambuco (CPRH) } \\
\hline \multicolumn{3}{|l|}{ 12. Secretaria do Patrimônio da União (SPU) } \\
\hline 13. Empresa de Turismo de Pernambuco (EMPETUR) & & \\
\hline
\end{tabular}

\section{Sociedade Civil}

Conselho

14. Fundação Pró-Tamar (TAMAR)

15. Centro Golfinho Rotador (CGR)

16. Assembleia Popular Noronhense (APN)

17. Associação Noronhense de Taxistas (NORTAX)

18. Associação Noronhense de Pesca (ANPESCA)

19. Associação de Condutores de Ecoturismo de Fernando de Noronha (ACITUR)

20. Associação de Barcos de Turismo de Fernando de Noronha (ABATUR)

21. Associação Desenvolvimento Agroecológico de FN (Noronha-Terra)

22. Associação de Hospedarias Domiciliares de Fernando de Noronha (AHDFN)

23. Instituto Ambiental de Fernando de Noronha (IAFENO)

24. Associação das Lanchas de Atividades Marítimas (ALAMAR)

25. Associação de Artistas e Artesãos de Fernando de Noronha (ASSAFEN)

26. Associação dos Receptivos

27. Associação Noronhense das Empresas de Mergulho Autônomo (ANEMA)

28. Centro de Pesquisa Histórica e Cultural de Fernando de Noronha (CEPEHC)

29. Centro Cultural Dona Nanete

30. Associação de Bares e Restaurantes de Fernando de Noronha (ABRENO)

FONTE: Os autores. 
Em relação ao ICMBio,o objetivo é a gestão das áreas marinhas protegidas, conciliando a preservação das UCs com a atividade humana.O órgão encontra-se em uma situação conflituosa com a comunidade por representar a fiscalização do território, como afirma um dos entrevistados do NGI-Noronha/ICMBio:

A comunidade noronhense é muito mista. Muito heterogênea. Então você vai ter vários públicos. Obviamente, cada um com seu interesse. O meio ambiente está em disputa. [...] O recurso que a ilha tem de melhor aqui não é o diamante, é a beleza cênica. Todo mundo quer ter o privilégio de explorar isso, ao mesmo tempo em que a natureza precisa do tempo pra se recompor. E a gente é o guardião da natureza. É como se nós fossemos os seguranças da mina de diamante. Então o nosso trabalho é muito difícil. A gente está aqui mediando conflito. Todo mundo está disputando um pedaço desse território.

Ao acompanhar as reuniões internas entre ICMBio, ATDEFN, SPU e CPRH, observou-se que a CPRH tem maior proximidade com a ATDEFN devido ao foco de administrar o uso e ocupação da APA através do licenciamento ambiental.Há ainda uma discrepância no contato entre CPRH e ICMBio no que diz respeito aos processos de licenciamento da APA, devido à lentidão nas respostas do ICMBio, uma vez que os pareceres deveriam passar pela Coordenação Regional do ICMBio em Cabedelo (CR6-PB), mesmo com equipe técnica presente no NGI-Noronha/ICMBio. O trecho de uma reunião técnica com a CPRH resume este conflito e exemplifica a participação do MPPE na ilha:

O MPPE sempre foi um parceiro com a comunidade e as instituições. Se fazia uma "consultoria" do MPPE. E o procurador sempre foi muito solicito e com muita paciência esclarecia. Chegou um momento que se viu "não há mais necessidade de comunicar [o ICMBio] porque nós temos dois ou três ofícios do gestor dizendo que na zona urbana não é necessário autorização", certo? Vinha a autorização de Cabedelo [CR-6], o núcleo daqui [NGI-Noronha] não expedia essa autorização. [...] Então nessas oportunidades em que precisamos do ICMBio, a gente extrapolou em muito o prazo legal. Tanto é que teve até a participação do governador do Estado interferindo nessa questão porque a gente não podia mais esperar.

Porém, a CPRH apresenta um histórico de ausência na fiscalização das atividades da APA, sua atribuição conforme o SISNAMA. O MPPE, responsável pela defesa do atendimento à legislação, teve papel crucial nos últimos anos, principalmente no que tange ao cumprimento de um Termo de Ajuste de Conduta (TAC) para adequações ambientais. Além disso, também representa o papel mediador ao aconselhar os órgãos públicos, como resume o trecho de entrevista abaixo:

Antes de mim tinha uma promotora de justiça que passou aqui 6 anos. Nós intensificamos bastante a atuação do MPPE aqui porque eu sempre tive uma preocupação ambiental muito grande. E aí assim que cheguei a minha primeira providência foi solicitar apoio técnico, pois o grande problema o que encontramos aqui foi a questão do lixo. O ICMBio estava desenvolvendo seu papel. A CPRH estava totalmente ausente. Situação que gerou a demanda nossa de 2016 na definição do papel de cada órgão ambiental. [...] Mas a atuação do MPPE aqui na ilha tem sido sempre no sentido de minimizar os conflitos, intermediar, conversar, nunca se sentindo dono da verdade. Enfim fazendo exercer o papel do MPPE. Sendo duro quando necessário. Flexível e facilitador de conversa entre os órgãos que tem suas diferentes atribuições. 
Outro órgão ausente na gestãoem anos anteriores foi a SPU, a qual atualmente tem como demanda regularizar o acordo de cessão de uso feito em 2002 entre SPU e ATDEFN, após recomendação da Controladoria Geral da União (CGU), do Tribunal de Contas da União ${ }^{2}$ e investigação do Ministério Público sobre instalações comerciais irregulares nas faixas de praia ${ }^{3}$. Porém, em oficina da SPU aberta à comunidade para a realização de um novo acordo de gestão compartilhadaem 2017, observou-se uma postura não participativa da ATDEFN com a SPU. De acordo com entrevista realizada com representante da SPU-PE, a equipe pretendia inserir o plano de manejo como exigência para anuência da SPU em projetos e definir um plano de fiscalização em parceria com ICMBio/ATDEFN, suprindo a omissão da SPU:

A SPU tem cadeira desde a criação e vinha sempre. Mas o gestor que participou não dava relevância. Eu não estava aqui na época. Mas é consenso que ele não trazia nenhuma informação e não tinha nenhum desdobramento (sobre os temas) na SPU.

O mosaico obtido a partir dessas observações permitiu agrupar as instituições de acordo com seus focos de atuação. ATDEFN e CPRH atuam na gestão de serviços urbanos, turismo e demais atividades econômicas da APA. O ICMBio tem maior atuação no ordenamento e fiscalização ambiental, porém suas atividades acabamse voltado mais para o PARNAMAR, onde não há conflito com a
ATDEFN. MPPE e SPU atuam como instituições reguladoras com poder mediador entre os demais atores. Em relação aos órgãos mediadores, observou-se maior articulação política entre ICMBio/ SPU (esfera federal) e MMPE/ATDEFN (esfera estadual). Essas informações geraram a valoração apresentada em MIDI e 2MAO (Figura 4A e B). A Figura 4C demonstra os agrupamentos identificados considerando essas características.

Considerando a atuação das instituições ATDEFN e ICMBio, identificou-se que ambos os órgãos apresentam melhor comunicação com órgãos das mesmas esferas e possuem as seguintes divergências: focos de atuação distintos e baixa interação (Tabela 4).

Apesar destas divergências, ATDEFN e ICMBio são responsáveis por 3 objetivos em comum: (1) Planejamento territorial/Regulação do uso e ocupação do território; (2) Promoção do conhecimento e envolvimento da comunidade na questão ambiental; (3) Fomento à pesquisa e manejo relacionado ao desenvolvimento sustentável. Ao analisar a mobilização destes atores em relação a esses objetivos, pode-se dizer que, em linhas gerais, a atuação do ICMBio apresenta maior peso.

A Tabela 5 apresenta um resumo sobre a atuação das instituições a partir das observações feitas durante a coleta de dados. Essas informações serviram de base para a valoração da atuação das instituições frente aos objetivos (mobilização) apresentado em histograma na Figura 5.

${ }^{2}$ TCU - Tribunal de Contas da União. Acórdão TCU 10840/2016.

${ }^{3}$ MPF - Ministério Público Federal. Inquérito civil n 1.26.000.000785/2002-29. 


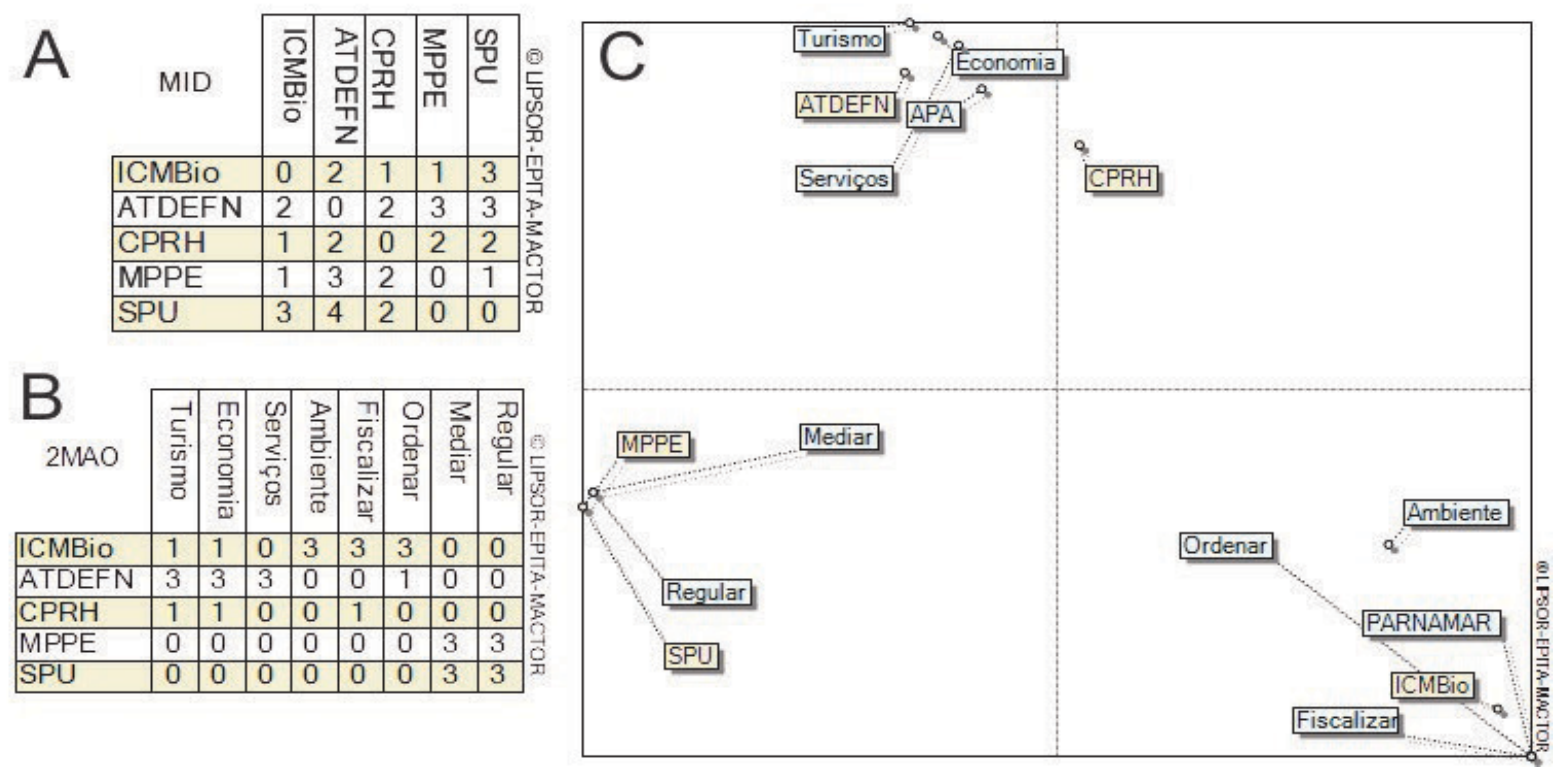

FIGURA 4 - A: Matriz de Influência Direta (MID) e B: Matriz de Posições Valoradas (2MAO) entre os atores e os objetivos estratégicos identificados, onde as influências são classificadas de 0 a 4 de acordo com o nível de intensidade. C: Mapa de correspondência entre atores e seus principais focos de atuação: três agrupamentos identificáveis entre ATDEFN/CPRH, MPPE/SPU e ICMBio.

FONTE: Elaborado pelos autores através do software Mactor.

TABELA 4 - Caracterização da interação entre a administração local (ATDEFN) e o gestor das UCs federais (ICMBio), principais atores institucionais na gestão de Fernando de Noronha.

\begin{tabular}{|c|c|}
\hline ATDEFN & ICMBio \\
\hline $\begin{array}{l}\text { Comunica-se bem com o Conselho Distrital pela temática social. } \\
\text { No viés ambiental, comunica-se bem com a CPRH e pouco com o } \\
\text { ICMBio. Com o MPPE articula-se bem e cumpre as determinações. } \\
\text { Com a SPU, vem estabelecendo contato para adequação do contrato } \\
\text { de cessão e uso, porém as tratativas são difíceis. }\end{array}$ & $\begin{array}{l}\text { Procura comunicação com ATDEFN, mas articula-se pouco. Com } \\
\text { a CPRH, a interaçáo é muito fraca. O MPPE é ouvido, porém não } \\
\text { tem competência para determinar ações. A SPU pode ser vista como } \\
\text { parceira para cobrança de ações da ATDEFN no que tange o uso do } \\
\text { território. }\end{array}$ \\
\hline
\end{tabular}

FONTE: Os autores. 
TABELA 5 - Resumo da atuação do ICMBio e ATDEFN frente aos objetivos identificados.

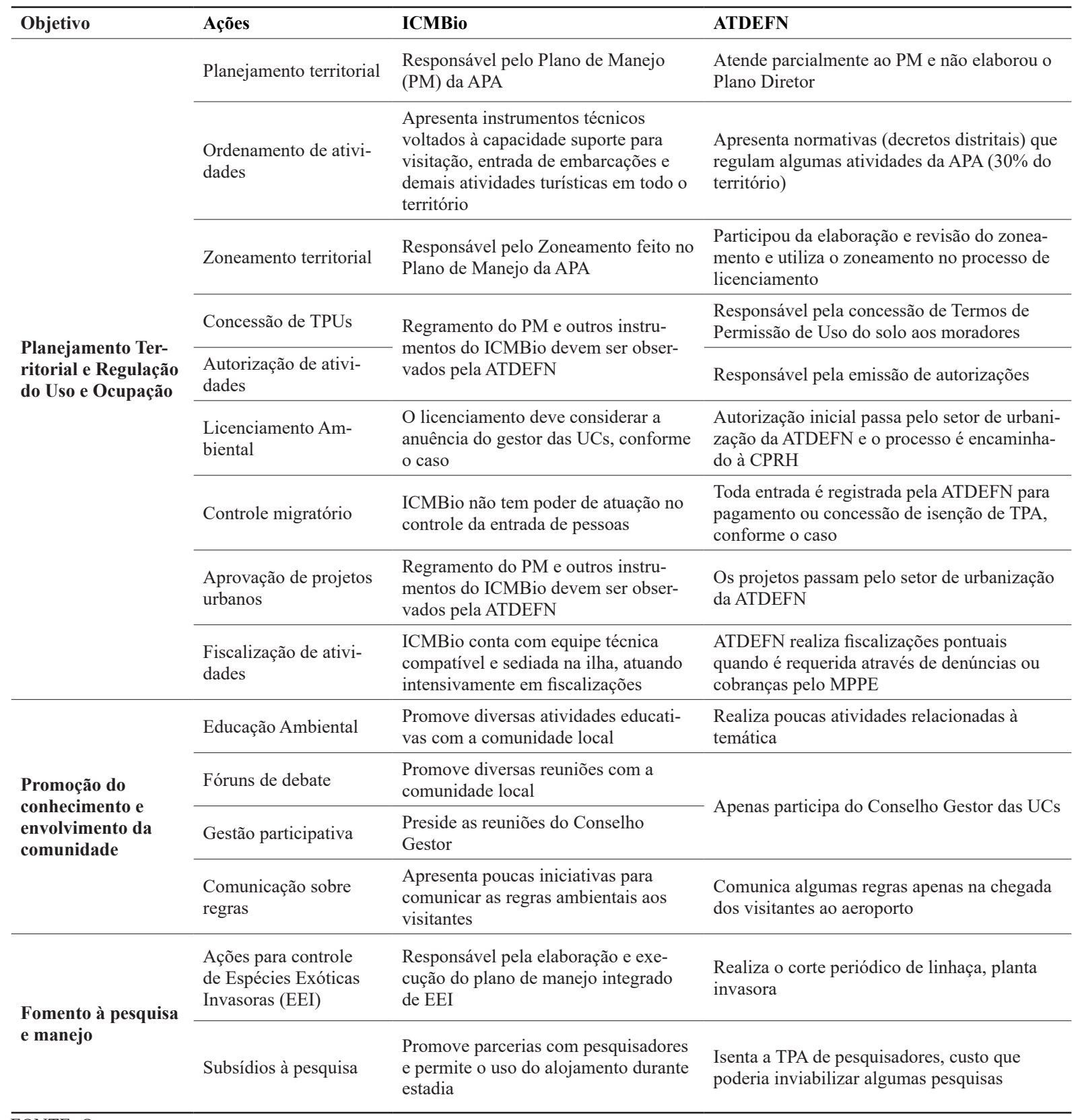

FONTE: Os autores. 


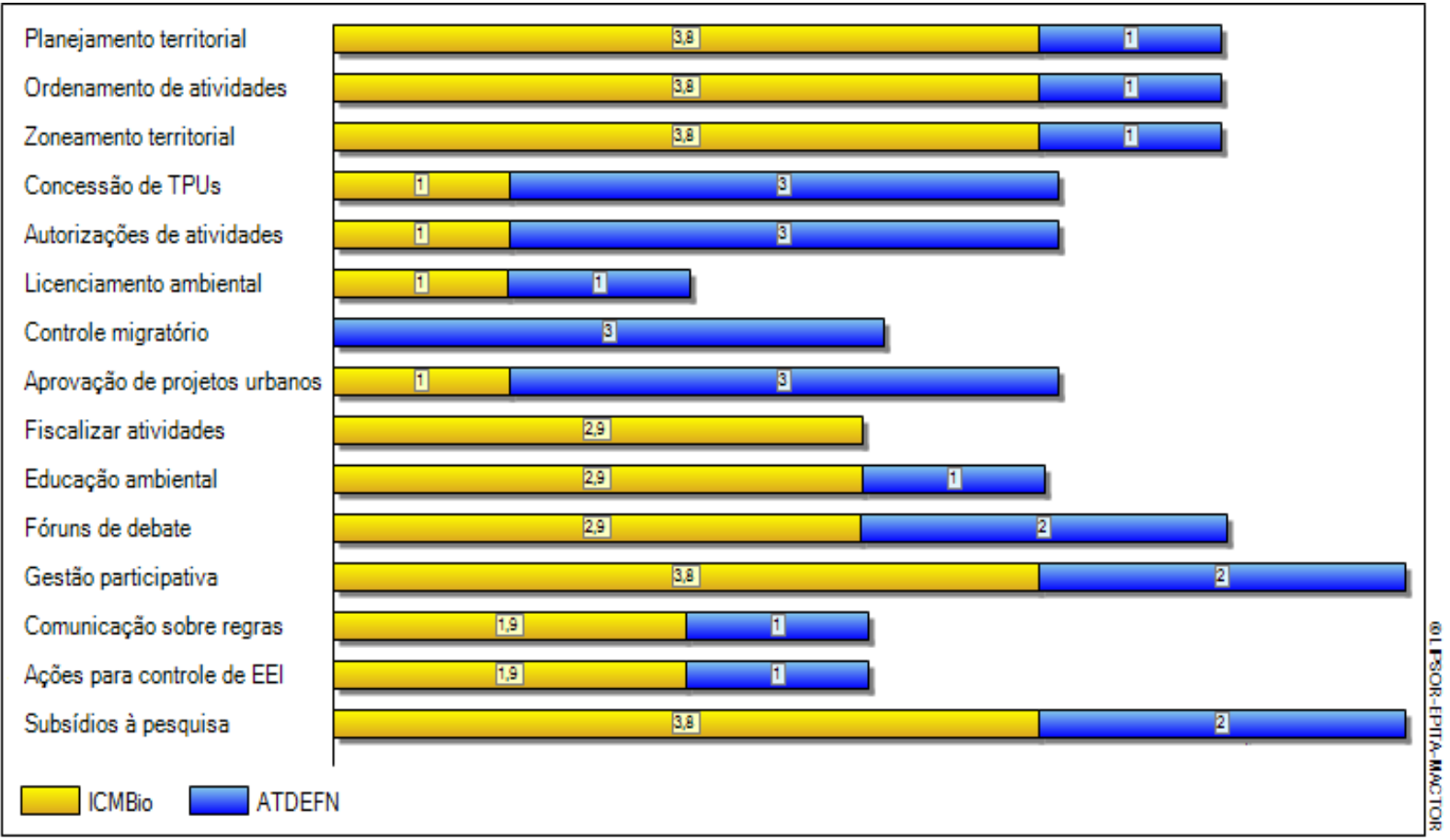

Figura 5 - Histograma de mobilização dos atores centrais ICMBio e ATDEFN, onde os valores representam a soma, em valores absolutos, dos pesos atribuídos aos atores em cada objetivo.

FONTE: Os autores.

Em suma, observou-se que o ICMBio é responsável pela elaboração de todos os documentos regulatórios sobre o uso e ocupação no arquipélago, pois ambas as UCs, apesar de categorias diferentes, são federais. Da mesma forma, o ICMBio atua na promoção da Gestão Participativa através do Conselho Consultivo e outras iniciativas de interação com a comunidade local. A instituição também é responsável por realizar fiscalização em todo o arquipélago, mas encontra resistência em fiscalizar a APA, pois compete com a responsabilidade do Estado, representado pela CPRH. A ATDEFN alega que a prioridade da fiscalização na APAé da CPRH, o que de fato está previsto na Lei Complementar 140/2011
(BRASIL, 2011) e na estrutura do SISNAMA. Porém, a instituição nunca teve sede na ilha e foram observadas apenas algumas ações fiscalizatórias pontuais relacionadas ao processo de licenciamento ambiental de alguns empreendimentos. Além disso, a ATDEFN não apresenta, até os dias atuais, o Plano Diretor da APA. Esse instrumento deveria ser usado no regramento da urbanização da APA, porém, ao invés disso, a ATDEFN utiliza o zoneamento do Plano de Manejo, elaborado pelo ICMBio.

Percebe-se no histograma da Figura 5 que o ICMBio está presente em todas as ações relacionadas aos três objetivos, com exceção do controle migratório. Porém, para compreensão da realidade, 
é importante esclarecer que as ações relacionadas à ocupação da APA, como controle migratório, concessão de TPU, autorização de atividades econômicas, licenciamento ambiental e aprovação de projetos urbanos, são aquelas que mais impactam o meio ambiente e geram problemas/conflitos socioambientais. Assim, apesar de o ICMBio apresentar maior poder de mobilização nas ações com relevância ambiental, a ATDEFN mostra-se o ator-chave com maior influência na regulação dos impactos provenientes da ocupação humana em Fernando de Noronha.

Este cenário de relações entre ICMBio e ATDEFN é parte da explicação para os problemas observados em Noronha. A desconexão verificada na atuação destas instituições públicas tem potencial de geração de conflitos na comunidade, pois os moradores não compreendem totalmente a responsabilidade de cada instituição, além de terem que conviver com uma estrutura urbana precária que diverge daquela oferecida aos turistas.

\subsection{Dimensão material: contexto socioambiental}

A presente análise faz uso do conceito de problema ambiental para determinar situações em que haja risco e/ou dano social e/ou ambiental sem nenhum tipo de reação dos responsáveis frente ao problema (Carvalho \& Scotto, 1995). Parte-se da premissa que o homem depende de recursos ambientais para sua sobrevivência, naturalmente limitados e por isso escassos. Ao elucidar-se a tônica das relações sociais, onde a apropriação e uso de recursos ambientais depende de interesses, necessidades, racionalidades, poderes, custos e benefícios em jogo, obtém-se a simples consequência da disputa por aquilo que não é abundante, e, então, problemas ambientais dão origem a conflitos socioambientais (Quintas, 2006).

Fernando de Noronha vive um período focado no turismo - e por ele regido. Nesse cenário, os impasses sociais aliam-se a problemas ambientais comuns nos dias de hoje. Indicadores de impactos como a extrapolação da capacidade de carga dos ambientes e perturbações de habitats marinhos indicam a vulnerabilidade ambiental local, sobre-exploração de ambientes naturais e a diminuição da capacidade suporte (Zanirato \& Tomazzoni, 2014).

Na perspectiva social, como conclui também Cleto (2013), tem-se o ressentimento dos ilhéus com os empresários continentais, pois, ao mesmo tempo em que sua sobrevivência financeira depende dos empresários, os ilhéus enxergam que os "bônus" do sistema, como boas casas, carros e barcos, recaem sobre os meios de vida atingidos pelos empresários e oferecidos aos turistas. Essa descrença é intensificada pela omissão do Estado em prover os serviços básicos urbanos, em não deixar claro suas normas reguladoras e ainda ao perpetuar o viés clientelista da administração pública (Cordeiro \& Körössy, 2018). Assim, ouvem-se as frases recorrentes: "Pra eles (turistas) tem tudo" e "Tudo na ilha vira dinheiro", gerando problemas de todas as ordens.

Cabe ressaltar que a sociedade civil apresenta significativa organização legal, porém, a simples existência de conselhos e instituições não garante a efetiva participação social (Drumond et al., 2009; Aburto et al., 2017). Apesar de bem estabelecidas e em pleno funcionamento, as reuniões do conselho APA/PARNAMAR apresentam características preocupantes como: (1) pautas sem fechamento prático para a tomada de decisão, (2) conselheiros 
representando interesses individuais e (3) baixa representatividade efetiva da comunidade local. Essa percepção foi observada em diferentes entrevistados, como demonstra o comentário abaixo:

Da primeira vez que eu vim me chamou atenção à quantidade de associações existentes, o que num primeiro momento me pareceu uma coisa positiva, posto que houvesse aí uma sociedade civil organizada. Mas à medida que fui convivendo com a ilha, eu já não achei a ideia tão boa. Porque na verdade são entidades que na maioria das vezes não tem uma pauta bem definida de reivindicações e as entidades entre si competem pelas mesmas coisas. Eu me lembro que associação de barqueiro tinha mais de uma. Então quando começa a ter várias entidades pode ser uma coisa personalista, pessoas que querem se promover. Não estou dizendo que é o caso desta ou outra associação, mas permite essa interpretação. Então isso me chamou a atenção. Uma vez que tem vários interlocutores, você não consegue 'interlocutar' de uma forma apropriada.

No perfil turístico de Noronha, observa-se a conformação de um jogo de interesses de grupos de atores com influência sobre a administração local que leva à concentração de renda e, muitas vezes, manipulação da dinâmica social e institucional administrativa. Essa situação, além de gerar conflitos sociais (Tabela 6) através de disputa e exclusão, agrava o crescimento populacional e a pressão sobre a ocupação do solo, gerando uma nova ordenação espacial.

O Estudo de Capacidade Suporte (Abdala, 2008) aponta limitações quanto ao uso e ocupação da APA, ou seja, da área urbanizada da ilha. Verifica-se uma situação de crescimento urbano mal

TABELA 6 - Resumo dos conflitos sociais observados em Fernando de Noronha.

\begin{tabular}{ll}
\hline Tema & Conflito social \\
\hline A cultura da pesca e agricultura em Noronha é tão antiga quanto sua história (Aragão, 1950 apud Cleto, \\
2013). Com a criação do PARNAMAR, a agricultura foi proibida em 70\% do territórioe a abertura da ilha ao \\
turismo em 1990 conformou a única atividade econômica viável. Atualmente, uma "recessão turística"inde- \\
pendente de suas causas pode representar um colapso social local, tamanha a dependência da comunidade. \\
Rinâmica socioeconômi- $\begin{array}{l}\text { Rechasileiro (2013) ainda apontam que o contraste socioeconômico entre moradores e visitantes re- } \\
\text { ca do turismo } \\
\text { sulta em uma gradual exclusão social da comunidade de certos processos e benefícios advindos da atividade, } \\
\text { criando-se uma percepção ambígua dos turistas por parte dos ilhéus. O turismo ainda trouxe um embate cul- } \\
\text { tural entre os migrantes fundadores de Noronha ("nativos"), os migrantes recém-chegados e a crescente gama } \\
\text { de turistas, entrecortando as fronteiras de pertencimento da comunidade devido aos comportamentos não } \\
\text { coerentes com a vida comunitária tradicional da ilha (Lima, 2008). }\end{array}$ \\
\hline
\end{tabular}

Ilhas são bens da União e, por isso, inalienáveis, imprescritíveis, impenhoráveis e insuscetíveis de serem onerados (Saule Júnior \&Fontes, 2006). Ou seja, ninguém pode comprar um terreno em Noronha, portanto o bem mais procurado pelos investidores legalmente não pode ser valorado. Apenas moradores permanentes, ou seja, residentes há mais de 10 anos, tem direito ao uso da terra através do Termo de Permissão de Uso concedido

Situação fundiária e disputa territorial pela ATDEFN (DEFN, 2004). Essa situação cria uma disputa territorial entre os moradores alimentado pela especulação imobiliária de investidores do continente, conformando um "mercado negro" de terrenos: empresários associam-se informalmente aos donos de TPUs e constroem grandes empreendimentos hoteleiros. Mercado semelhante também ocorre através da venda de autorizações para a entrada de automóveis na ilha. Fato também observado por Falcão (2010), Cleto (2013) e Cordeiro \& Gomes (2016).

FONTE: Os autores. 
planejado, devido à ausência ou ao não cumprimento de normas gerais de urbanização e edificação (Andrade et al., 2009). Nesse espaço há falta de água, encarecimento do custo de vida, aumento do número de pousadas e veículos, diminuição da segurança, além de problemas sociais, como o aumento do uso de álcool e drogas, baixa solidariedade entre os moradores e, principalmente, o aumento populacional de residentes, levando à escassez de moradia e limitação do serviço médico-hospitalar (Souza \& Vieira Filho, 2011). Resumidamente, os três pontos apresentados no trecho de entrevista a seguir sintetizam a realidade da ilha:

De um lado uma natureza exorbitante de bonita, de um lado uma sociedade com muito poder econômico construindo coisas de alto nível e de outro uma população envolvida na prestação de serviços cada vez mais próxima da miséria e da favela a despeito de recursos financeiros que possam ter. A partir do momento que você começa a ter esse tipo de situação, não é difícil que você passe a ter problemas ambientais.

Com base em índices que apontam a vulnerabilidade ambiental, o Estudo de Capacidade Suporte considerou que, em 2006, a capacidade de carga da ilha era de 2.556 pessoas e apresentava, à época, uma sobrecarga de 1.444 pessoas. Partindo de um cenário de excelência, onde todos os problemas apontados fossem resolvidos, Noronha teria uma a capacidade global de carga populacional de 6 mil pessoas (Abdala, 2008). É importante salientar que poucas melhorias no sistema urbano, como saneamento básico, foram feitas desde então.

Entre 2000 e 2007, as instruções normativas da ATDEFN passaram o limite máximo diário de visitantes de 130 para 246 (DEFN, 2007) pessoas (média de 7.400/mês), mostrando como a pressão do setor econômico é capaz de modificar as regras estabelecidas. O atual Plano de Manejo da APA (ICMBio, 2017) acata o limite diário de 246 visitantes (89.000 visitantes/ano), porém observa-se que esse limite também não é respeitado. De 1995 a 2016, a entrada de turistas na ilha passou de 21.315 para 91.194 visitantes ao ano. Esses dados mostram que o sistema de controle migratório estabelecido na ilha apenas contabiliza estes números para administrar o pagamento da Taxa de Preservação Ambiental. Ainda que de forma não precisa, a entrada de visitantes é controlada pelo número de voos, disponibilidade de pousadas e pela TPA, cujos valores são responsáveis pela limitação de mercado.

Este aumento de turistas demanda o aumento de residentes para que os serviços turísticos possam ser oferecidos. Com o aumento de residentes e turistas, a quantidade de veículos cresce na mesma proporção, indicador que, conforme Abdala (2008), reflete a "expansão socioeconômica desenfreada". As locadoras de veículos são consideradas o segundo "equipamento turístico" mais importante na ilha, depois das pousadas. De 1990 a 2007, houve um aumento de aproximadamente $600 \%$, passando de 150 veículos registrados no DETRAN-PE para 900. Em dezembro de 2016, conforme DETRAN-PE, havia na ilha 1.250 veículos registrados, dos quais 327 eram motocicletas e 533 automóveis.

Por regra da ATDEFN, a concessão de novas autorizações para entrada de veículos está suspensa desde 2002, permitindo apenas a permuta de autorizações já existentes. Esses dados mostram que a suspensão não barrou a entrada de novos automóveis (DEFN, 2002).

Apesar da existência de controle migratório, não foram encontrados registros oficiais atuais sobre a população residente. Dados do IBGE referentes 
ao censo de 2010 apontavam 2.630 pessoas residentes, com uma estimativa para o ano de 2020 de 3.101 habitantes. Considerando os últimos números divulgados, existem em torno de 4.800 residentes (Neiva, 2016) e uma média de 8.833 visitantes por mês, visto que em 2019 a ilha recebeu 106.000 turistas (Marinho, 2020a). Assim, estima-se uma população total que flutue em torno de 13.000 pessoas, muito além da capacidade suporte de 6 mil. O trecho de entrevista a seguir demonstra a percepção da comunidade em relação ao aumento abrupto da população:
Agora final do ano (2016) vamos ter mais 12 mil pessoas na ilha. Se tivemos mais de 8 mil visitantes em outubro como vimos na reunião do CONTUR, e os moradores já chegaram a mais de 4 mil, com certeza teremos sim mais de 12 mil pessoas na ilha.

A extrapolação da capacidade suporte da ilha foi identificada como o fator responsável pelo agravamento de problemas ambientais tipicamente urbanos existentes na ilha (Tabela 7), como a gestão inadequada de resíduos sólidos e efluentes, o aumento na demanda energética baseada em queima de óleo diesel (termoelétrica) e a introdução de espécies exóticas invasoras.

TABELA 7 - Contextualização dos problemas ambientais observados em Fernando de Noronha.

\begin{tabular}{ll}
\hline Tema & Problemas ambientais \\
\hline & $\begin{array}{l}\text { Em 2016, a média mensal de lixo recebido na Unidade de Tratamento de Resíduos Sólidos era de 300-330 toneladas, } \\
\text { onde 250 toneladas são caracterizadas como domiciliar, } 60 \text { toneladas são 'volumosos', 20 toneladas de restos de podas }\end{array}$ \\
$\begin{array}{l}\text { Resíduos Sólidos aproximadamente 50 toneladas de rejeito. Existia um passivo ambiental de 2 mil toneladas, ou seja, compartimentos } \\
\text { Urbanos (RSU) } \\
\text { de lixo enterrados ao longo do terreno da usina, resultado de anos de má gestão, que estavam sendo enviados, aos } \\
\text { poucos, ao continente (Fonte: gestor da unidade de tratamento de resíduos). }\end{array}$
\end{tabular}

\begin{abstract}
Estações de tratamento de

O estudo de capacidade suporte da APA apontou que as instalações existentes são incompatíveis nos aspectos quantitaefluentes (ETEs) tivos e qualitativos em médio prazo, seja do ponto de vista de proteção ao meio ambiente quanto ao grau de depuração dos esgotos. Também mostra a precariedade do sistema, cuja instalação é antiga, o tratamento é apenas primário e não abrange $100 \%$ do esgoto gerado. Os vazamentos de esgoto das ETES são recorrentes, mesmo após inúmeros autos de infração lavrados.
\end{abstract}

\begin{tabular}{ll}
\hline & A energia elétrica na ilha começou a ser distribuída a partir da década de 1980 com a construção da Usina Termoe- \\
& létrica Tubarão, administrada pela Companhia de Eletricidade de Pernambuco (CELPE). A usina foi reformada após \\
& incêndio em 2007, e em 2016 supria a demanda de $91 \%$ da ilha. Operando no limite de suas condições, possui capaci- \\
Matriz & dade de geração instalada de 4,372MW + 1,12MW, com um total de 5 geradores, consumindo anualmente em torno de \\
energética & 4,15 milhões de litros de óleo. Entre 2013 e 2014, a geração de energia ultrapassou $16 \mathrm{GWh}$, totalizando um consumo \\
& de óleo diesel superior a 4,5 milhões de litros. O restante da demanda energética é suprido por duas usinas de geração \\
& fotovoltaica, capazes de reduzir o consumo de 200 mil litros de diesel por ano (Napoleão \& Neto, 2016).
\end{tabular}

\section{Espécies exóti- cas invasoras (EEI) da fauna e flora}

Noronha encontra-se entre as 10 UCs brasileiras com maior número registrado de invasão por espécies exóticas: 22 espécies (Guimarães, 2015). Recentemente, um plano integrado do ICMBio propõe medidas de controle, mas nem todas estão sendo aplicadas (ICMBio, 2019).

FONTE: Os autores. 


\subsection{A interação das três dimensões}

A análise aqui realizada concentrou-se em explicitar o contexto de cada dimensão investigada. Porém, como observa Frey (2000), na realidade política da gestão pública, essas dimensões são entrelaçadas e se influenciam mutuamente. A dimensão institucional fornece a base para que a dimensão processual se configure, gerando, consequentemente, resultados na dimensão material. A Figura
6 demonstra essa relação e resume os pontos mais importantes levantados em cada dimensão.

Em linhas gerais, pode-se afirmar que a dimensão institucional se mostra bem implementada e altamente especializada, pois apresenta bom arranjo institucional com definições claras dos órgãos públicos envolvidos, rico arcabouço jurídico e participação social organizada através de associações que participam ativamente de conselhos temáticos abertos à comunidade.

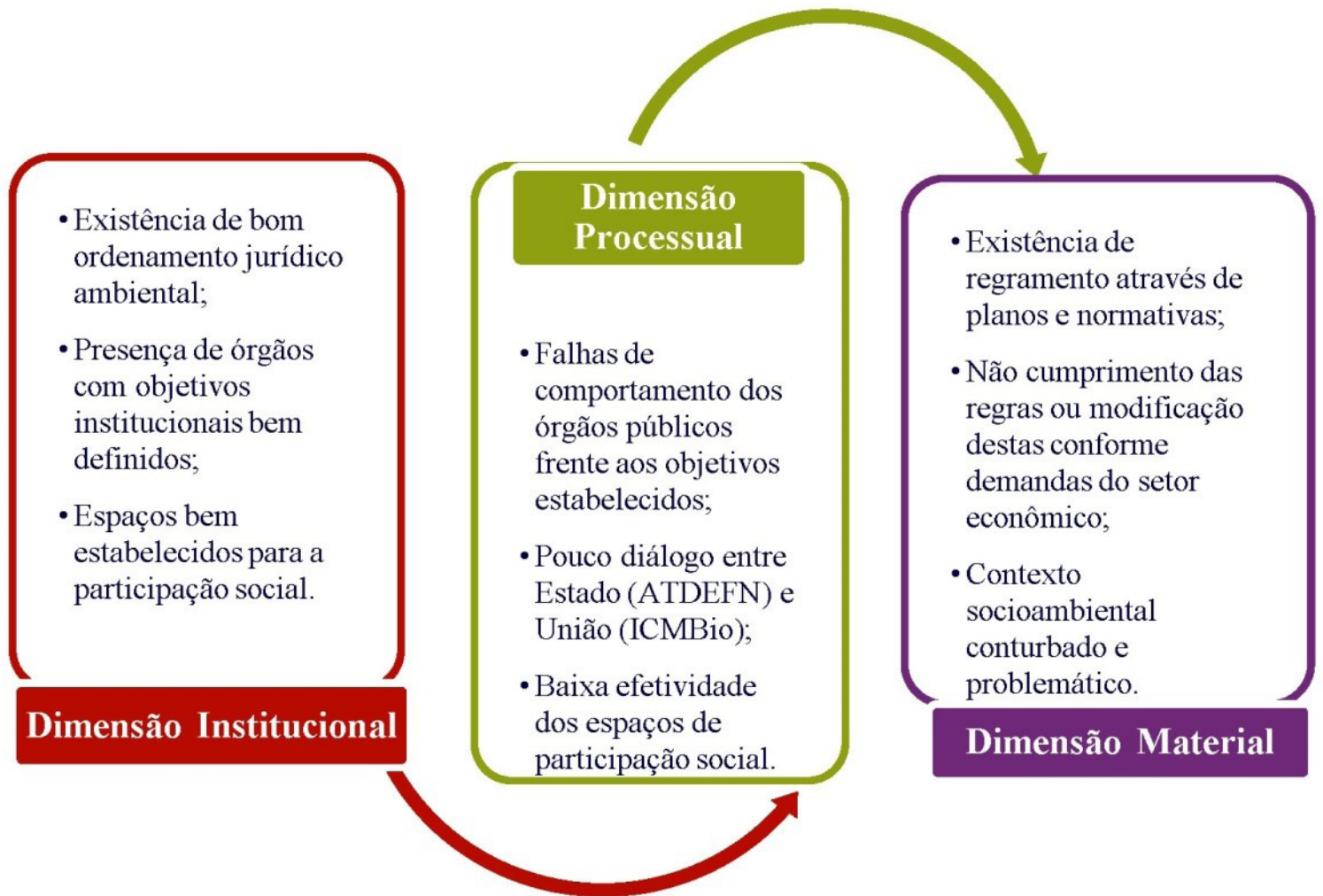

FIGURA 6 - Quadro-resumo das análises realizadas por este estudo sobre cada dimensão da gestão ambiental pública de Fernando de Noronha, onde as setas indicam o fluxo de influência de uma dimensão sobre a outra.

FONTE: Os autores. 
Já no que tange à dimensão material, as ferramentas de gestão e planejamento mostram-se concretas pela presença de planos de manejo (APA e PARNAMAR) e regramentos específicos para as atividades de uso e ocupação do território (Estudos de Capacidade Suporte, Portarias ICMBio, Decretos Distritais ATDEFN, Agenda Ambiental Noronha+20), mas sua efetivação nem sempre pode ser aferida. Muitos projetos não "saem do papel" e acabam caindo em um verdadeiro "cemitério de ideias" como afirma Cleto (2013). Esses fatos levam ao contexto socioambiental da ilha observado em diversos estudos (Abdala, 2008; Falcão, 2010; Cleto, 2013; Cordeiro \& Gomes, 2016; Cordeiro \& Körössy, 2018), onde problemas ambientais e conflitos sociais confirmam a existência de falhas no cumprimento das regras estabelecidas no arquipélago.

Portanto, a dimensão que mais necessita de atenção é a processual, visto que existe uma relação conflituosa entre a gestão do Estado (ATDEFN) e da União (ICMBio) que acaba por prejudicar o alcance do sistema de governança implementado. O principal problema a ser trabalhado é o formato de atuação dos órgãos gestores ATDEFN e ICMBio, pois é preciso dirimir as falhas de comportamento identificadas em ambos os órgãos (Figura 7).

As falhas identificadas na atuação das instituições comprometem o funcionamento do sistema de governança estabelecido na gestão das UCs. A boa governança em uma área marinha protegida depende, entre outros fatores, de um planejamento minucioso, de habilidades pessoais, de uma boa mobilização social, do comprometimento dos atores locais e da representatividade dos espaços de gestão participativa, onde o monitoramento do grau de participação pode ser feito através da definição de indicadores (Drumond, 2009). Os exemplos identificados nas reuniões dos conselhos indicam que, apesar de positiva, a gestão compartilhada traz dificuldades que podem resultar no agravamento de conflitos. Algumas características preocupantes

Autarquia do Distrito Estadual de Fermando de Noronha (ATDEFN)

-Historicamente, apresenta pouca ação na temática ambiental;

- Assume posturas paliativas em relação aos problemas ambientais;

- Acata reinvindicações do trade turístico e altera regramento de uso e ocupação;

-Articula pouco com o ICMBio e não acata medidas restritivas propostas.

Núcleo de Gestão Integrada de Fermando de Noronha (ICMBio)

- Volta a maior parte dos recursos técnicos para ações no PARNAMAR;

- Sem atuação efetiva na área da APA por falta de articulação com ATDEFN;

- Apresenta histórico de conflito com a comunidade local por fiscalizações;

- Depende de decisões tomadas pela administração regional do ICMBio.

Figura 7 - Quadro-resumo das falhas de comportamento identificado nos atores-chave do sistema de Gestão de Fernando de Noronha. FONTE: Os autores. 
observadas podem servir como sinais de alerta aos gestores. Dessa forma, a Tabela 8 apresenta alguns indicadores e situações de alerta que podem ser utilizados pelos gestores noronhenses em direção à implementação de uma governança efetiva e responsável.

Por fim, considerando o histórico da ilha, seu contexto social e administrativo, a solução para as falhas apontadas na governança ambiental de Fernando de Noronha concentra-se no equilíbrio de gestão entre meio ambiente, comunidade local e o turismo, fato sintetizado no comentário de um morador e empresário da ilha:
Eu também já falei muito mal do ICMBio. Mas agora vou falar bem. [...] Nós já tivemos grandes gestores do parque aqui. Tivemos uma integração muito boa entre a comunidade e o ICMBio. Eu tenho saudade dessa época. [...] Quando você fala de gestão integrada me lembra outra coisa. Vocês falam a nível de geografia, das duas UCs, mas isso também faz lembrar que nada em Fernando de Noronha vai funcionar se não tiver o avanço integral das três vertentes que eu valorizo aqui, que são: meio ambiente, comunidade e a nossa indústria do turismo. Uma das três coisas, enquanto for indiferente, não vai funcionar.

TABELA 8 - Indicadores para a gestão de conflitos no âmbito da governança nas UCs de Fernando de Noronha com base em diretrizes do MMA e da IUCN.

\begin{tabular}{|c|c|}
\hline Indicador & Situação de Alerta \\
\hline $\begin{array}{l}\text { Capacidade de envolvimento do gestor público com a comunidade } \\
\text { local e visitantes }\end{array}$ & $\begin{array}{l}\text { Baixa adesão comunitária às atividades socioambientais } \\
\text { desenvolvidas }\end{array}$ \\
\hline $\begin{array}{l}\text { Sentimento de pertencimento frente às iniciativas socioambientais } \\
\text { do poder público }\end{array}$ & $\begin{array}{l}\text { Atores referem-se às iniciativas como "alheia",com ressentimento ou } \\
\text { sem identificação pessoal }\end{array}$ \\
\hline $\begin{array}{l}\text { Participação de atores com diferentes níveis de conhecimento } \\
\text { técnico e cultural }\end{array}$ & $\begin{array}{l}\text { Participantes do projeto não expressam suas próprias opiniões e } \\
\text { delegam a decisão a atores mais notáveis }\end{array}$ \\
\hline $\begin{array}{l}\text { Habilidade de servidores públicos articularem-se e estabelecerem } \\
\text { acordos }\end{array}$ & $\begin{array}{l}\text { Relações são expressas por meio de não atendimento a solicitações, } \\
\text { discordâncias e até discussões }\end{array}$ \\
\hline $\begin{array}{l}\text { Percentual de parcerias entre atores locais devido a iniciativas da } \\
\text { gestão pública }\end{array}$ & $\begin{array}{l}\text { Atores locais, mesmo atuando nos mesmos canais de gestão } \\
\text { participativa, não tem contato entre si }\end{array}$ \\
\hline $\begin{array}{l}\text { Existência de ferramentas de comunicação institucional com a } \\
\text { comunidade local }\end{array}$ & $\begin{array}{l}\text { Maioria dos moradores não tem conhecimento destas ferramentas de } \\
\text { comunicação ou não têm contato }\end{array}$ \\
\hline $\begin{array}{l}\text { Tempo médio para construção de produtos finais em processos } \\
\text { participativos da gestão }\end{array}$ & $\begin{array}{l}\text { Demora prejudicial à execução ou aplicação do produto final é } \\
\text { causada por divergências entre atores, que demandam mecanismos de } \\
\text { baixo custo para resolução de conflitos }\end{array}$ \\
\hline
\end{tabular}

FONTE: Adaptado de Drumond (2009) e Borrini-Feyerabend et al. (2014). 


\section{Conclus̃̃es}

Em Fernando de Noronha, observam-se três problemas principais na temática ambiental: (1) Uso irrestrito de recursos ambientais, enquanto regras são mudadas para ajuste às demandas turísticas; (2) Ineficiência da gestão pública, explicada por sua governança desconexa; (3) Descrença da comunidade local no poder mediador do Estado, devido ao histórico de atuação do poder público.

O formato de turismo consolidado na ilha, aliado a falhas de governança, pode ser visto como a pressão/ameaça mais atuante nas AMPs de Noronha. Esse formato não valoriza a história local, a mão de obra ilhéu ou o conhecimento tradicional do pequeno núcleo restante, além de não respeitar os limites ambientais impostos pelas UCs, mesmo utilizando o PARNAMAR como principal holofote de venda de seus produtos. Esses fatores foram observados também por ICMBIO (2008), Cleto (2013), Feitosa \& Gómez (2013), Cordeiro \& Gomes (2016) e Cordeiro \& Körössy (2018). Assim, pode-se inferir que ecoturismo não é a principal atividade, que a limitação de visitantes não restringe o aumento da demanda e que as pousadas não são mais exclusivamente familiares (Körössy, 2007; Ashton \& Ashton, 2016).

O cenário político em termos de meio ambiente tornou-se ainda mais complexo e precário desde 2019, quando a ausência da atuação do Ministério do Meio Ambiente em diversas agendas tem respaldado ações que são, na verdade, opostas às suas próprias atribuições (Escobar, 2019a; Disner \& Torres, 2020; Soares et al., 2020). Tal situação afeta a gestão em Noronha, dado o papel relevante do ICMBio. A gestão 2019-2022do governo fede- ral demonstra uma nítida falta de interesse com as agendas ambientais, quando não uma motivação "antiambiental" na retórica e na prática que vão contra as tendências mundiais voltadas à conservação e sustentabilidade (Escobar, 2019b). Nessa gestão, existe um plano de reestruturação do ICMBio, onde, entre outras atividades, prevê-se a troca de técnicos de carreira por indicações políticas, em maioria militares (Bragança \& Menegassi, 2020). Tais mudanças advêm, em regra geral, do foco de atuação do Ministério do Meio ambiente em ampliar o turismo nas áreas protegidas, principalmente em Noronha.

Porém, a pandemia do COVID-19 trouxe novos indícios de que os problemas da ilha estão diretamente ligados ao turismo descontrolado. Pela primeira vez desde a abertura ao turismo, a ilha observou a suspensão da entrada de turistas e fluxo de moradores, uma das medidas adotadas pelo Governo Estadual (PE) para frear a disseminação do vírus (Pernambuco, 2020). Até maio de 2020, foram contabilizados 2 meses sem o fluxo de turistas e moradores temporários (trabalhadores), restando uma população residente próxima a 3 mil pessoas. Marinho (2020a, 2020b, 2020c, 2020d e 2020e) e Meireles (2020) apontam alguns impactos considerados positivos nesta situação, como, por exemplo: diminuição da visitação de praias no PARNAMAR, diminuição da população residente, diminuição na geração de lixo (RSU) e melhora no abastecimento de água potável aos moradores.

Por fim, deve-se ressaltar o fato de que em Fernando de Noronha se observa uma sociedade vulnerável a embates políticos e problemas ambientais, carente em infraestrutura e serviços públicos, dependente da administração local devido ao isolamento geográfico e com um crescente potencial 
econômico, cujas características tornam a relação entre todos os envolvidos complexa e altamente competitiva. Sob essa ótica, a única estratégia possível para a gestão noronhense é ter uma boa governança, considerada aqui nas três dimensões analisadas, como seu principal mecanismo de ação.

\section{Referências}

Abdala, G.C. Estudo e determinação da capacidade de suporte e seus indicadores de sustentabilidade com vistas à implantação do plano de manejo da área de proteção ambiental do arquipélago de Fernando de Noronha, 2009. Brasília: ICMBio; MMA. Disponível em: <http://saf.avaliacao.org.br/content/files-xmls/pjs/331/publicacoes/187/ Capacidade $\% 20 \mathrm{de} \% 20$ Suporte $\% 20-\% 20$ Estudo $\% 20 \mathrm{e} \% 20$ Determina\%C3\%A7\%C3\%A3o.pdf>. Acesso em: mai. 2021.

Aburto, J. A.; Gaymer, C. F.; Cundill, G. Towards local governance of marine resources and ecosystems on Easter Island. Aquatic Conservation, 27(2), 353-371, 2017. Disponível em: https://agris.fao.org/agris-search/search. do?recordID $=$ US201800147103

Almeida, F. F. M. de. Ilhas oceânicas brasileiras e suas relações com a tectônica atlântica. Terra e Didatica, 2(1), 3-18, 2015. doi: 10.20396/td.v2i1.8637462

Andrade, L. M. S.; Gomes, V. G.; Dias, M. B. Desafios para o futuro sustentável da ilha de Fernando de Noronha: a visão ecossistêmica da ocupação urbana. Oculum Ensaios, 9, 86105, 2009. Disponível em: https://seer.sis.puc-campinas. edu.br/seer/index.php/oculum/article/view/353/333

Ashton, E. G.; Ashton, M. S. G. Gerenciamento de resíduos sólidos no destino turístico Fernando de Noronha, Brasil. Anais Brasileiros de Estudos Turísticos-ABET, 6(2), 82-96, 2016. Disponível em: https://periodicos.ufjf.br/index.php/ abet/article/view/3146

Bennett, N. J.; Dearden, F. Why local people do not support conservation: Community perceptions of marine protected area livelihood impacts, governance and management in
Thailand. Marine Policy, 44, 107-116, 2014.

Borrini-Feyerabend, G.; Dudley N.; Jaeger, T.; Lassen, B.; Pathak, N.; Phillips, A.; Sandwith, T. Governance of Protected Areas: From understanding to action. Best Practice in Protected Areas Guidelines Series, Suiça: IUCN, vol. 20, 2014. Disponível em: <https://portals.iucn.org/library/ sites/library/files/documents/PAG-020.pdf > . Acesso em: ago. 2021.

Bragança, D.; Menegassi, D. Nanico e militarizado, reestruturação do ICMBio entra em vigor. $O E c o, 12$ de maio de 2020. Disponível em: <https://www.oeco.org.br/ reportagens/nanico-e-militarizado-reestruturacao-do-icmbio-entra-em-vigor/>. Acesso em: ago. 2021.

Brasil. Decreto Lei $n .{ }^{\circ} 92.755$, de 5 de junho de 1986. Declara Área de Proteção Ambiental o Território Federal de Fernando de Noronha, o Atol das Rocas e os Penedos de São Pedro e São Paulo. Brasília: DOU de 5/6/1986.

Brasil. Constituição da República Federativa do Brasil, de 5 de outubro de 1988. 11. ed. São Paulo, Atlasm 1988a.

Brasil. Decreto Lei $n .{ }^{\circ}$ 96.693, de 14 de setembro de 1988. Cria o Parque Nacional Marinho de Fernando de Noronha. Brasília: DOU de 14/9/1988b.

Brasil. Lei complementar $n^{\circ} 140$, de 8 de dezembro de 2011. Fixa normas, nos termos dos incisos III, VI e VII do caput e do parágrafo único do art. 23 da Constituição Federal, para a cooperação entre a União, os Estados, o Distrito Federal e os Municípios nas ações administrativas decorrentes do exercício da competência comum relativas à proteção das paisagens naturais notáveis, à proteção do meio ambiente, ao combate à poluição em qualquer de suas formas e à preservação das florestas, da fauna e da flora; e altera a Lei no 6.938, de 31 de agosto de 1981. Brasília: DOU de 09/12/2011.

Brasil. Lei $n .^{\circ}$ 9.985, de 18 de julhode 2000. Institui o Sistema Nacional de Unidades de Conservação. Brasília: DOU de 18/7/2000.

Bursztyn, M. A.; Bursztyn, M. Fundamentos de política e gestão ambiental: caminhos para a sustentabilidade. Rio de Janeiro: Garamond, 2012.

Cárcamo, P. F.; Garay-Flühmann, R.; Squeo, F. A.; Gaymer, 
C. F. Using stakeholders' perspective of ecosystem services and biodiversity features to plan a marine protected area. Environmental Science \& Policy, 40, 116-131, 2014. doi: 10.1016/j.envsci.2014.03.003

Cardoso, L. S.; Alarcon, D. T.; Campiolo, S.; Schiavetti, A. Governança ambiental e percepção sobre processos participativos na Reserva Extrativista de Canavieiras, Bahia, Brasil. Desenvolvimento e Meio Ambiente, 50, 170-191, 2019.

Cardozo, L. S.; Porto, M. F.; Pimentel, P. C. B.; Rodrigues, J. S.; Schiavetti, A.; Campiolo, S. Discussões do Conselho Deliberativo da Reserva Extrativista de Canavieiras, Bahia, Brasil: da gestão pesqueira à ambiental. Journal of Integrated Coastal Zone Management, 12(4), 463-475, 2012.

Carvalho, I.; Scotto, G. Conflitos socioambientais no Brasil (Vol. I). Rio de Janeiro: Ibase, 1995.

Carvalho, R. G. A.; Decol, F. G.; Fruet, L.; Lanzer, R. M. Um estudo sobre as atividades turísticas em seis ilhas brasileiras. Revista Brasileira de Pesquisa em Turismo, 10 (1), 173-188, 2016.

Cavalcanti, C. Economia e ecologia: problemas da governança ambiental no Brasil. Revista de La Red Ibero americana de Economia Ecológica, 1, 1-10, 2004. Disponível em: https://ddd.uab.cat/pub/revibec/revibec_a2004v1/ revibec_a2004v1a5.pdf

Cleto, A. W. De cemitério de ideias a embrião de sementes: uma experiência sobre a mobilização social em Fernando de Noronha. Brasília, Dissertação (Mestrado em Turismo) - UnB, 2013.

Cordeiro, I. D.; Gomes, E. T. A. A dinâmica da produção do espaço pelo turismo em Fernando de Noronha (Pernambuco/ Brasil) e suas consequências. Revista Turismo y Desarrollo, 20, 2016. Disponível em: http://www.eumed.net/rev/turydes/20/pernambuco.html

Cordeiro, I.; Körössy, N. Quando as políticas públicas de turismo sustentável ignoram a dimensão social: reflexões a partir do estudo caso de Fernando de Noronha (Pernambuco - Brasil). Caderno Virtual de Turismo. Dossiê temático Turismo, Natureza e Cultura: diálogos interdisciplinares e políticas públicas. Rio de Janeiro, 18(3), 40-56, 2018. doi: $10.18472 /$ cvt.18n3.2018.1555
Di Franco, A.; Thiriet, P.; Di Carlo, G.; Dimitriadis, C.; Francour, P.; Gutiérrez, N.L.; Jeudy De Grissac, A.; Koutsoubas, D.; Milazzo, M.; Otero, Md.M.; Piante, C.; Plass-Johnson, J.; Sainz-Trapaga, S.; Santarossa, L.; Tudela, S.; Guidetti, P. Five key attributes can increase marine protected areas performance for small-scale fisheries management. International Journal of Scientific Reports, 6, 38135, 2016.

Disner, G.R.; Torres, M. The environmental impacts of 2019 oil spill on the Brazilian coast: Overview. Revista Brasileira de Gestão Ambiental e Sustentabilidade, 7(15), 241-255, 2020.

DEFN - Distrito Estadual de Fernando de Noronha. Decreto distrital $n^{\circ} 003$, de 22 de julho de 2002. Disciplina o ingresso e a permanência de veículos automotores de passageiros e de motocicletas, bem como o serviço de transporte de passageiros e locação de veículos no Distrito Estadual de Fernando de Noronha. Fernando de Noronha: DOE de 24/01/03.

DEFN - Distrito Estadual de Fernando de Noronha. Decreto distrital $n^{\circ} 018$ de 06 de fevereiro de 2004. Estabelece procedimentos, condições e requisitos, para o reconhecimento da não-incidência da Taxa de Preservação Ambiental, no âmbito do Distrito Estadual de Fernando de Noronha. Fernando de Noronha: DOE de 06/02/04.

DEFN - Distrito Estadual de Fernando de Noronha. Instrução normativa $n^{\circ} 002$ de 22 de maio de 2007. Altera dispositivo da Instrução Normativa $n^{0} 01 / 2000$, de 01 de fevereiro de 2000. Fernando de Noronha: DOE de 22/05/07.

Drumond, M. A.; Giovanetti, L.; Queiroz, A. Técnicas e Ferramentas Participativas para a Gestão de Unidades de Conservação. Brasília: MMA, 2. ed., 2009. Disponível em: $<$ http://ava.icmbio.gov.br/pluginfile.php/108/mod_data/ content/2681/Caderno_4_-_ARPA.pdf $>$. Acesso em: ago. 2021 .

Ehler, C. N. Indicators to measure governance performance in integrated coastal management. Ocean \& Coastal Management, 46 (3-4), 335-345, 2003. doi: 10.1016/S09645691(03)00020-6

Epstein, G.; Pittman, J.; Alexander, S.M.; Berdej, S.; Dyck, T.; Kreitmair U.; Raithwell, K.; Villamayor-Tomas, S; Vogt, J.; Armitage, D. Institutional fit and the sustainability of 
social-ecological systems. Current Opinion in Environmental Sustainability, 14, 34-40, 2015. doi: 10.1016/j. cosust.2015.03.005

Escobar, H. Bolsonaro's first moves have Brazilian scientists worried. Science, 363, 330, 2019a. doi: 10.1126/ science.363.6425.330

Escobar, H. Mysterious oil spill threatens marine biodiversity haven in Brazil, Science, 2019b. doi: https://doi. org/10.1126/science.aba1003

Falcão, M. A sustentabilidade do destino turístico de Fernando de Noronha: uma análise a partir da abordagem do ciclo de vida de áreas turísticas e das dimensões da sustentabilidade. Recife, Dissertação (Mestrado em Administração) - UFPE, 2010.

Feitosa, M. J. S.; Gómez, C. R. P. Aplicação do Tourism Ecological Footprint Method para avaliação dos Impactos Ambientais do Turismo em Ilhas: um estudo em Fernando de Noronha. Revista Brasileira de Pesquisa em Turismo. São Paulo, 7(2), 220-238, 2013. doi: 10.7784/rbtur.v7i2.509

Figueiredo, L. T.; Nicolodi J. L. O Desenvolvimento de um Modelo de Avaliação de Boas Práticas de Gestão Costeira Integrada como Base para a Gestão. Revista Costas, 2(2), 9-30, 2020.

Fournier, J.; Panizza, A. C. Contribuições das áreas marinhas protegidas para a conservação e a gestão do ambiente marinho. Raega - O Espaço Geográfico em Análise, 7, 2003. doi: 10.5380/raega.v7i0.3351

Frey, K. Políticas públicas: um debate conceitual e reflexões referentes à prática da análise de políticas públicas no Brasil. Planejamento e Políticas Públicas. 21, 211-259, 2000. Disponível em: http://desafios2.ipea.gov.br/ppp/index.php/ PPP/article/view/89

Giakoumi, S.; McGowan, J.; Mills, M.; Beger, M.; Bustamante, R.H.; Charles, A.; Christie, P.; Fox, M.; Garcia-Borboroglu, P.; Gelcich, S.; Guidetti, P.; Mackelworth, P.; Maina, J.M.; McCook, L.; Micheli, F.; Morgan, L.E.; Mumby, P.J.; Reyes, L.M.; White, A.; Grorud-Colvert, K.; Possingham, H.P. Revisiting "success" and "failure" of marine protected areas: a conservation scientist perspective. Frontiers in Marine Science, 5, 1-5, 2018. doi: 10.3389/ fmars.2018.00223
Glaser, M.; Breckwoldt, A.; Carruthers, T. J.; Forbes, D. L; Costanzo, S.; Kelsey.Towards a framework to support coastal change governance in smallislands. Environmental Conservation, 45(3), 227-237, 2018.

Godet, M. Actors moves and strategies: The mactor method: An air transport case study. Futures, 23(6), 605-622, 1991. doi: 10.1016/0016-3287(91)90082-D

Godet, M.; Durance, P. A Prospectiva Estratégica para Empresas e Territórios. Paris: Dunod; Unesco, 2015. Disponível em: $<$ http://www.laprospective.fr/dyn/traductions/ contents/findunod-godet-durance-ext-vpt.pdf $>$. Acesso em: ago. 2021.

Guimarães, T. C. S. Espécies exóticas invasoras da fauna em unidades de conservação federais no Brasil: sistematização do conhecimento e implicações para o manejo. Brasília, Dissertação (Mestrado em Ecologia) - UNB, 2015.

Hall, P.; Taylor, R. Political science and the three new institutionalism. Political Studies, 5(44), 936-957, 1996.

IBAMA - Instituto Brasileiro do Meio Ambiente e dos Recursos Naturais Renováveis. Plano de Manejo - APA Fernando de Noronha - Rocas - São Pedro e São Paulo. Brasília, 2005. Disponível em: $<$ https://www.icmbio.gov. br/portal/images/stories/plano-de-manejo/plano_de_manejo_parna_ferando-de-noronha.pdf $>$. Acesso em: maio 2020.

IBGE - Instituto Brasileiro de Geografia e Estatística. Panorama: Cidades. Brasília, 2020. Disponível em: $<$ https://cidades.ibge.gov.br/brasil/pe/fernando-de-noronha/ panorama>. Acesso em: ago. 2021.

ICMBIO - Instituto Chico Mendes de Conservação da Biodiversidade. Estudo e determinação da capacidade de suporte e seus indicadores de sustentabilidade com vistas à implantação do plano de manejo da área de proteção ambiental do arquipélago de Fernando de Noronha. Brasília: Ministério do Meio Ambiente, 2008.

ICMBIO - Instituto Chico Mendes de Conservação da Biodiversidade. Portaria $n^{\circ}$ 7, de 3 de janeiro de 2017. Institui o Núcleo de Gestão Integrada de Fernando de Noronha - ICMBio Noronha, um arranjo organizacional de unidades de conservação (UC) federais do Instituto Chico Mendes de Conservação da Biodiversidade. Brasília: DOU de $3 / 1 / 2017 a$. 
ICMBIO - Instituto Chico Mendes de Conservação da Biodiversidade. Plano de Manejo da Área de Proteção Ambiental (APA) de Fernando de Noronha-Rocas - São Pedro e São Paulo. Brasília: Ministério do Meio Ambiente, 2017b.

ICMBIO - Instituto Chico Mendes de Conservação da Biodiversidade. Portaria $n^{\circ}$ 58, de 4 de fevereiro de 2019. Aprova o Plano de Ação para o Controle de Gatos (Feliscatus) na Área de Proteção Ambiental de Fernando de Noronha - Rocas - São Pedro e São Paulo e no Parque

Nacional Marinho de Fernando de Noronha, estabelecendo seu objetivo geral, objetivos específicos, prazo de execução e formas de implementação, supervisão e revisão. Brasília: DOU de 22/02/2019.

ICMBIO - Instituto Chico Mendes de Conservação da Biodiversidade. Cadastro Nacional de Unidades de Conservação. 2020. Disponível em: <https://dados.gov.br/dataset/ unidadesdeconservacao $>$. Acesso em: out. 2020.

Jones, P. J. S.; Murray, R. H.; Vestergaard, O. Enabling Effective and Equitable Marine Protected Areas: guidance on combining governance approaches. Ecosystems Division, UN Environment. 2019. Disponível em: <https://wedocs. unep.org/bitstream/handle/20.500.11822/27790/MPA. pdf? sequence=1\&isAllowed=y > . Acesso em: abr. 2021 .

Kelleher, G. Guidelines for marine protected areas. Suiça: IUCN; Reino Unido: Cambridge, 1999.

Kokkranikal, J.; McLellan, R. Island Tourism and Sustainability: A Case Study of the Lakshadweep Islands. Journal of Sustainable Tourism, 11(5), 426-447, 2010.

Körössy, N. Turismo e recursos hídricos no arquipélago de Fernando de Noronha (Pernambuco/Brasil): Reflexões sobre a sustentabilidade da atividade turística a partir da análise do consumo de água pelos meios de hospedagem. Recife, Dissertação (Mestrado em Gestão e Políticas Ambientais) - UFPE, 2007.

Lima, J. C. R. A simbologia triádica de Fernando de Noronha. Cadernos de Estudos Sociais, 24(2), 287-298, 2008. Disponível em: https://periodicos.fundaj.gov.br/CAD/ article/view/1410

Lima Filho, J. F. Turismo em Áreas Marinhas Protegidas: O Perfil dos Visitantes do Parque Estadual Marinho da Pedra da Risca do Meio. Fortaleza, Monografia (Graduação em Gestão de Empreendimentos Turísticos). Centro Federal de Educação Tecnológica do Ceará, 2006.

Lobão, R. Cosmologias políticas do neocolonialismo: como uma política pública pode se transformar em uma política do ressentimento. Brasília, Tese (Doutorado em Antropologia Social) - UnB, 2006.

Macedo, H. S. Processos Participativos na gestão de áreas protegidas: estudo de caso em unidades de conservação de uso sustentável da zona costeira do Sul do Brasil. Florianópolis, Dissertação (Mestrado em Sociologia Política) - UFSC, 2008.

Marinho, A. C. Plano de Manejo autoriza a abertura de novas pousadas em Fernando de Noronha. Blog Viver Noronha, 2017. Disponível em: <http://g1.globo.com/pernambuco/ blog/viver-noronha/post/plano-de-manejo-autoriza-abertura-de-novas-pousadas-em-fernando-de-noronha.html $>$. Acesso em: ago. 2021.

Marinho, A. C. Fernando de Noronha recebe mais de 106 mil turistas no ano de 2019. Blog Viver Noronha, 2020a. Disponível em:<https://g1.globo.com/pe/pernambuco/blog/ viver-noronha/post/2020/01/28/fernando-de-noronha-recebe-mais-de-706-mil-turistas-ao-longo-de-2019.ghtml $>$. Acesso em: ago. 2021.

Marinho, A. C. Com redução de pessoas cai $50 \%$ a produção de lixo de Fernando de Noronha. Blog Viver Noronha, 06 de abr. de 2020b. Disponível em: <https:/g1.globo.com/pe/ pernambuco/blog/viver-noronha/post/2020/04/06/com-reducao-de-pessoas-cai-em-50percent-a-producao-de-lixo-de-fernando-de-noronha.ghtml>. Acesso em: ago. 2021.

Marinho, A. C. Rodízio de abastecimento de água em Fernando de Noronha é reduzido para combater o coronavírus. Blog Viver Noronha, 2020c. Disponível em: $<$ https://g1.globo.com/pe/pernambuco/blog/viver-noronha/ post/2020/03/23/rodizio-de-abastecimento-de-agua-em-fernando-de-noronha-e-reduzido-para-combater-o-coronavirus.ghtml>. Acesso em: ago. 2021.

Marinho, A. C. Turistas são retirados de praias de Fernando de Noronha pela PM por causa do novo coronavírus. Blog Viver Noronha, 2020d. Disponível em: <https://g1.globo. com/pe/pernambuco/blog/viver-noronha/post/2020/03/21/ 
turistas-sao-retirados-de-praias-de-fernando-de-noronha-pela-pm.ghtml>. Acesso em: ago. 2021.

Marinho, A. C. Ministério público determina retirada imediata de moradores irregulares em Noronha. Blog Viver Noronha, 2020e. Disponível em: <https://g1.globo. com/pe/pernambuco/blog/viver-noronha/post/2020/04/17/ ministerio-publico-de-pe-determina-retirada-imediata-de-moradores-irregulares-em-fernando-de-noronha.ghtml>. Acesso em: ago. 2021.

Meireles, M. Decreto suspende atividades de turismo em Fernando de Noronha para prevenção ao coronavírus. G1, 20 de mar. de 2020. Disponível em: <https://g1.globo.com/ pe/pernambuco/noticia/2020/03/20/decreto-suspende-atividades-de-turismo-em-fernando-de-noronha-para-prevencao-ao-coronavirus.ghtml>. Acesso em: ago. 2021.

MMA-Ministério do Meio Ambiente. Portaria no. 9, de 23 de janeiro de 2007. Reconhece áreas prioritárias para a conservação, utilização sustentável e repartição de benefícios da biodiversidade brasileira. Brasília: DOU de 23/01/2007.

Moura, A. M. M. Aplicação dos instrumentos de política ambiental no Brasil: avanços e desafios. In: Moura, A. M. M. (Org.). Governança ambiental no Brasil: instituições, atores e políticas públicas. Brasília: IPEA, p. 111-146, 2016. Disponível em: <https://www.ipea.gov.br/portal/ index.php?option $=$ com_content $\&$ view $=$ article $\& i d=28192>$. Acesso em: set. de 2020.

Napoleão, G. B.; Neto, A. C. Análise de Fluxo de Carga e Energia Gerada no Sistema Isolado da Ilha de Fernando de Noronha. Revista de Engenharia e Pesquisa Aplicada, 3(1), 2016. doi: 10.25286/repa.v3i1.275

Neiva, A. P. Fernando de Noronha chega a 513 anos com população crescente. Diário de Pernambuco, 2016. Disponível em: $<$ https://www.diariodepernambuco.com.br/noticia/ vidaurbana/2016/08/noronha-chega-a-513-anos-com-populacao-crescente.html>. Acesso em: ago. 2021.

Ogana, C. A.; Drumond, M. A.; Ferreira, M. N. (Orgs.). Management Effectiveness of Brazilian Federal Protected Areas: Results of 2010. Brasília: WWF-BRASIL; ICMBio, 2012.

Padovan, M. P.; Lederman, M. R. Análise da situação do manejo das Unidades de Conservação do Espírito Santo,
Brasil. In: Anais do IV Congresso Brasileiro de Unidades de Conservação, Curitiba, PR, 2004.

Pernambuco. Constituição do estado de Pernambuco, de 5 de outubro de 1989. Pernambuco: DOE de 5/10/1989a.

Pernambuco. Lei $n^{\circ} 10.403$, de 29 de dezembro de 1989. Institui os tributos no âmbito do Distrito Estadual de Fernando de Noronha, dispõe sobre a sua competência tributária e dá outras providencias. Pernambuco: DOE de 29/12/1989b.

Pernambuco. Decreto $n^{\circ} 48.822$, de 17 de março de 2020. Altera o Decreto $\mathrm{n}^{\circ} 48.809$, de 14 de março de 2020, que regulamenta, no Estado de Pernambuco, medidas temporárias para enfrentamento da emergência de saúde pública de importância internacional decorrente do coronavírus responsável pelo surto de 2019, conforme previsto na Lei Federal $n^{\circ} 13.979$, de 6 de fevereiro de 2020. Pernambuco: DOE de 17/03/2020.

Prado, D. S.; Araujo, L. G.; Chamy, P.; Dias, A. C. E.; Seixas, C. S. Participação Social nos Conselhos Gestores de Áreas Protegidas: Avanços normativos e a visão de agentes do ICMBio. Ambiente \& Sociedade, 23, 1-23, 2020.

Prates, A. P. L. Recifes de Coral e Unidades de Conservação Costeiras e Marinhas no Brasil: uma análise da representatividade e eficiência na conservação da biodiversidade. Brasília, Tese (Doutorado em Ecologia) - UnB, 2003.

Queiroz, M. H. Avaliação do Grau de Implementação das Unidades de Conservação da Ilha de Santa Catarina. In: Anais do III Congresso Brasileiro de Unidades de Conservação, Fortaleza, CE, 2002.

Quintas, J. S. Introdução à gestão ambiental pública. Brasília: IBAMA, 2006.

Rees, S. E.; Mangi, S. C.; Hattam, C.; Gall, S. C.; Rodwell, L. D.; Peckett, F. J.; Attrill, M. J. The socio-economic effects of a Marine Protected Area on the ecosystem service of leisure and recreation. Marine Policy, 62, 144-152, 2015. doi: 10.1016/j.marpol.2015.09.011

Reis, A.; Hayward, P. Pronounced particularity: a comparison of governance structures on Lord Howe Island and Fernando de Noronha. Island Studies Journal, 8(2), 285-298, 2013.

Rocha, J. M.; Brasileiro, I. L.G. Turismo em Fernando de 
Noronha - Uma visão de sustentabilidade a partir do estruturalismo. Revista Cenário, 1(1), 74-92, 2013. Disponível em: https://periodicos.unb.br/index.php/revistacenario/ article/download/15204/13515/\#page=74

Saule Junior, N.; Fontes, M. L. Manual de regularização fundiária em terras da União. São Paulo: Instituto Pólis; Brasília: Ministério do Planejamento, Orçamento e Gestão, 2006.

Silva, M. B. L. Fernando de Noronha: cinco séculos de história. Cadernos Noronhenses, CELPE, 1, 2007.

Soares, M. O.; Paiva, C. C.; Godoy, R. K. P.; Silva, M. B.; Castro, C. S. S. Gestão ambiental de ecossistemas insulares: O caso da Reserva Biológica do Atol das Rocas, Atlântico Sul Equatorial. Revista Gestão Costeira Integrada, 10(3), 347-360, 2010.

Soares, M. O.; Teixeira, C. E. P.; Bezerra, L. E. A.; Paiva, S. V.; Tavares, T. C. L.; Garcia, T. M.; Cavalcante, R. M. Oilspill in South Atlantic (Brazil): Environmental and governmental disaster. Marine Policy, 115, 103879, 2020.

Souza, R. M. G; Vieira Filho, N. A. Impactos socioculturais do turismo em comunidades insulares: Um Estudo de caso no Arquipélago de Fernando de Noronha-PE. 2011. Revista Acadêmica Observatório de Inovação do Turismo, 4, 5-5. Disponível em: http://bibliotecadigital.fgv.br/ojs/index.php/ oit/article/view/5805

Stevenson, T. C.; Tissot, B. N. Evaluating marine protected areas for managing marine resource conflict in Hawaii.
Marine Policy, 39, 215-223, 2013. Disponível em: https:// doi.org/10.1016/j.marpol.2012.11.003

Théret, B. As instituições entre as estruturas e as ações. Lua Nova: Revista de Cultura e Política, 58, 225-254, 2003.

Troiano, M.; Riscado, P. Instituições e o Institucionalismo: notas acerca da construção do debate e seus principais desafios na contemporaneidade. Revista Política Hoje, 25(1), 113-132, 2016.

UNESCO - Organização das Nações Unidas para a Educação, a Ciência e a Cultura. Brazilian Atlantic Islands, 2015. Disponível em: $<$ http://whc.unesco.org/en/list/1000>. Acesso em: ago. 2021.

Yates, K. L.; Clarkec, B.; Thurstan, R. H. Purpose vs performance: What does marine protected area success look like? Environmental Science and Policy, 92, 76-86, 2019. doi: 10.1016/j.envsci.2018.11.012

Zanirato, S.H.; Tomazzoni, E. L. A Sustentabilidade do Turismo em Fernando de Noronha (PE-Brasil). Turismo y Desarrollo Local, 17, 2014. Disponível em: https://www. eumed.net/rev/turydes/17/noronha.html 